Cohesion Policy and Inequality Dynamics:

Insights from a Heterogeneous Agents Macroeconomic Model

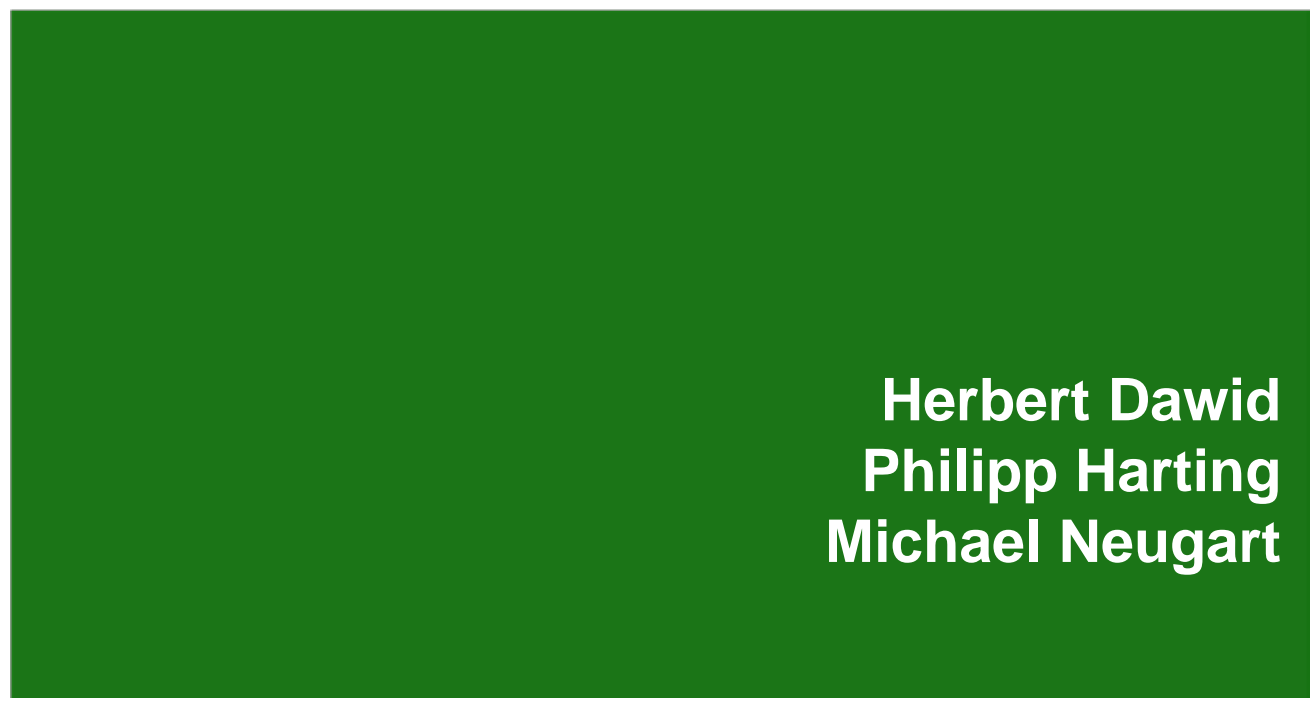


Herbert Dawid, Philipp Harting and Michael Neugart

Cohesion Policy and Inequality Dynamics: Insights from a Heterogeneous Agents Macroeconomic Model

SFB 882 Working Paper Series, No. 34

DFG Research Center (SFB) 882 From Heterogeneities to Inequalities

Research Project A4

Bielefeld, November 2014

SFB 882 Working Paper Series

General Editors: Martin Diewald, Thomas Faist and Stefan Liebig

ISSN 2193-9624

This publication has been funded by the German Research Foundation (DFG).

SFB 882 Working Papers are refereed scholarly papers. Submissions are reviewed by peers in a two-stage SFB 882 internal and external refereeing process before a final decision on publication is made.

The Working Paper Series is a forum for presenting works in progress. Readers should communicate comments on the manuscript directly to the author(s).

The papers can be downloaded from the SFB 882 website http://www.sfb882.uni-bielefeld.de/

SFB 882 "From Heterogeneities to Inequalities"

University of Bielefeld

Faculty of Sociology

PO Box 100131

D-33501 Bielefeld

Germany

Phone: +49-(0)521-106-4942 or +49-(0)521-106-4613

Email: office.sfb882@uni-bielefeld.de

Web: http://www.sfb882.uni-bielefeld.de/ 
DFG Research Center (SFB) "From Heterogeneities to Inequalities"

Whether fat or thin, male or female, young or old - people are different. Alongside their physical features, they also differ in terms of nationality and ethnicity; in their cultural preferences, lifestyles, attitudes, orientations, and philosophies; in their competencies, qualifications, and traits; and in their professions. But how do such heterogeneities lead to social inequalities? What are the social mechanisms that underlie this process? These are the questions pursued by the DFG Research Center (Sonderforschungsbereich (SFB)) "From Heterogeneities to Inequalities" at Bielefeld University, which was approved by the German Research Foundation (DFG) as "SFB 882" on May 25, 2011.

In the social sciences, research on inequality is dispersed across different research fields such as education, the labor market, equality, migration, health, or gender. One goal of the SFB is to integrate these fields, searching for common mechanisms in the emergence of inequality that can be compiled into a typology. More than fifty senior and junior researchers and the Bielefeld University Library are involved in the SFB. Along with sociologists, it brings together scholars from the Bielefeld University faculties of Business Administration and Economics, Educational Science, Health Science, and Law, as well as from the German Institute for Economic Research (DIW) in Berlin and the University of Erlangen-Nuremberg. In addition to carrying out research, the SFB is concerned to nurture new academic talent, and therefore provides doctoral training in its own integrated Research Training Group. A data infrastructure project has also been launched to archive, prepare, and disseminate the data gathered. 


\section{Research Project A4 "The Heterogeneity of Skills, Technological Change, and Changing Perspectives on the Labor Market"}

The goal of this project is to broaden and deepen our understanding of how technological progress influences various mechanisms that transform heterogeneities in formal qualification (general skills) into inequalities in pay. It accords particular attention to the differing dynamics of specific (nonobservable) skills.

The project studies this issue by developing an empirically founded, agent-based simulation model of a closed economy, allowing explicit modeling of the interaction between heterogeneous individuals under different institutional conditions and explaining aspects of economic dynamics, such as technological progress, as endogenous phenomena. The key facets of the concrete mechanisms to be observed in the simulation model are: (a) the enhancement of specific skills through dealing with technologies in the workplace (learning process), (b) feedback effects between the employee's general/specific skills and the employer's choice of technology, and (c) the transfer of information about jobs through social networks (social closure).

By using the simulation model, it is possible, in a first step, to analyze whether and how far various assumptions about technological progress influence these mechanisms, and thus to investigate the effect of heterogeneity in formal qualification on pay inequalities. One important point here is that the closed nature of the simulation model makes it possible to identify chains of effects that arise from feedback between various sectors of the economy. In a second step, the project will study the effects of various interventions by economic policy makers and institutions on the income dynamics of different skill groups.

The special benefits of this approach are twofold. The first is that the effect of three aspects on the genesis of pay inequalities can be analyzed simultaneously: endogenous technological progress; the endogenously generated, vertically differentiated labor demand and supply, and institutional interventions. This brings together analyses that have previously been conducted in isolation, and offers the opportunity to study feedback effects between the variables. The second benefit is that this approach can be expanded successively to cover a 12-year period. The goal is to endogenize the heterogeneities in formal qualification and thereby model and analyze their emergence. This makes it necessary to take a cross-generational view. 


\section{The Authors}

Herbert Dawid is Professor for Economic Theory and Computational Economics at Bielefeld University. He holds a doctoral degree from the Vienna University of Technology and held positions at the University of Vienna and the University of Southern California (Los Angeles) before moving to Bielefeld. His main research interests are agent-based modelling, economic dynamics, innovation economics, policy design and dynamic game theory. He has published extensively on these issues in leading international journals and is Co-Editor of the Journal of Economic Dynamics and Control, Associate Editor of Dynamic Games and Applications and member of several other Editorial and Advisory Boards.

Philipp Harting is research associate at Bielefeld University. He holds a Ph.D. degree in economics from the Bielefeld University. His main research interests include agent-based computational economics, innovation economics, labor economics and the study of fiscal and technology policies.

Michael Neugart is a professor of public economics and economic policy at the Technical University of Darmstadt. Before coming to Darmstadt he was an associate professor at the Free University of Bolzano, a senior research fellow at the Social Science Center Berlin, and John F. Kennedy Fellow at the Center for European Studies at Harvard University. His research interests are in the areas of labor, macroeconomics, and political economics. He published numerous articles in journals as the European Economic Review, the Journal of Economic Behavior and Organization, the Journal of Economic Dynamics and Control, or the European Journal of Political Economy. Michael is also a member of the editorial board of the European Journal of Political Economy. 


\title{
Cohesion Policy and Inequality Dynamics: Insights from a Heterogeneous Agents Macroeconomic Model*
}

\author{
H. Dawid P. Harting; and M. Neugart $^{\ddagger}$
}

November 2014

\begin{abstract}
Regions within the European Union differ substantially not only with respect to per capita GDP, but also with respect to income inequality within the regions. This paper studies the effects of different types of technology-oriented cohesion policies, aiming at the reduction of regional differences, on the convergence of regions and the dynamics of income inequality within regions. In particular, policies are analyzed using a two-region agent-based macroeconomic model - the Eurace@Unibi model - where firms in the lagging region receive subsidies for investment in physical capital. It is demonstrated that the short-, medium- and long-term effects of the policies on per-capita output and between as well as within regional inequality differ substantially depending on how successful the policy is in incentivizing firms to choose best available capital vintages and on how flexible labor markets are in the targeted region.
\end{abstract}

Keywords: cohesion policies, technology adoption, agent-based model, inequality

JEL Classification: C63, O33

${ }^{*}$ Financial support of the German Science Foundation (Collaborative Research Center (SFB) 882 "From Heterogeneities to Inequalities") is gratefully acknowledged.

${ }^{\dagger}$ Department of Business Administration and Economics and Institute of Mathematical Economics, Bielefeld University, Germany

${ }^{\ddagger}$ Department of Business Administration and Economics, Bielefeld University, Germany

$\S$ Department of Law and Economics, Technical University of Darmstadt, Germany 


\section{Introduction}

There is considerable inequality in terms of per capita income between European Union members states. Countries from Central Eastern Europe and Southern Europe are facing substantially lower per capita incomes than those from Western and Northern Europe. Moreover, we do not only observe income gaps between countries but unequally distributed incomes within countries ${ }^{1}$ Inter- as well as intra-regional inequality contributed to a questioning of the European integration project and also has put governments of single countries under pressure. Policymakers are striving for measures to alleviate these problems and a major pillar for fostering convergence of regions has been the European Regional Development Funds (ERDF). Empirically, however, the effectiveness of cohesion policy measures is contested (see e.g. Boldrin and Canova, 2001; Cappelen et al., 2003, Becker et al., 2010; Aiello and Pupo, 2012)

Since the eastern enlargement of the EU also the countries from Central Eastern Europe have access to these policy measures. These countries lag behind the Western European countries in terms of their per capita incomes. Moreover, in these countries income inequality seems to have increased since the fall of the iron curtain. Besides, they differ from the old member states in various other respects that may be important for the effectiveness of the cohesion policies. In particular, we see two potential candidates that may contribute to a different unfolding of transfers in the Eastern European Countries. First, we observe that labor markets in countries from Central Eastern Europe are characterized by an institutional setting different from the Western European countries. In particular, there occurs to be put a higher pressure on the unemployed to accept job offers as replacement rates in the new EU member states are lower than in Western European countries (van Vliet and Caminada, 2012) and more efforts seem to go into the activation of the unemployed (OECD, 2007). Secondly, the absorptive capacity to turn the transfers in per capita growth may differ from the old European countries. Here, we are mainly thinking along two dimensions. If firms receive subsidies for the investment of latest technologies, the potential productivity enhancements may not materialize due to a lack of human capital to actually run these technologies. Furthermore, not properly working public administrations may make it difficult to implement the policy along the intended lines. In conclusion, the measures within the ERDF are applied to a set of countries that is distinct from the ones in Western Europe and the question arises what we should expect in terms of the effects of the policies on these

\footnotetext{
${ }^{1}$ For more details, see our discussion in the following section.
} 
countries' per capita incomes and the income distribution.

In this paper, we analyze to which extent technology-oriented cohesion policies can help fostering convergence of per-capita incomes between regions and how they affect intra-regional inequality. Investigating the role of absorptive capacity of the targeted region we are able to vary the degree to which firms actually purchase technologies from the frontier, to control the quality of human capital they are able to draw from, and to analyze the outcomes of the technology policies with respect to the flexibility of the labor market of the region receiving the transfers.

The analysis is conducted within the Eurace@Unibi agent-based macroeconomic model. We believe that an agent-based macroeconomic model is the most appropriate tool to gain insights into the emergent dynamics with respect to the average income per capita and the income distributions in these regions. In particular the focus on implications of the policy on income inequality requires an approach able to capture the evolution of heterogeneities within households and firms in a region. 2 Whereas this evolution is naturally captured in an agent-based model, it is hard to do so in dynamic equilibrium models based on assumptions of representative agents. The Eurace@Unibi model describes an economy containing labor, an investment and a consumption goods sector, as well as a financial and a credit market in a regional context. Capital good firms provide investment goods of different vintages and productivities. Consumption good firms combine this capital with labor of varying degrees of general and specific skills to produce a consumption good that households purchase. Households' saved income goes into the credit and financial markets through which it is channeled to firms financing the production of goods. This framework allows us to use a strongly micro-founded model for the analysis of short-, medium- and long-run policy effects arising from heterogeneous and interacting firms and workers in a spatial context. We set up the model in a way that one region is initially endowed with a capital stock whose technological level is close to the frontier, while the other region's capital shows a considerable gap which the technology-oriented cohesion policies aim to close. This setup aims to capture in a stylized way the heterogeneity within the European Union with respect to productivity and endowment with human and physical capital.

Within this framework we explore the implications of policies which resemble measures implemented within the European Regional Development Fund (ERDF). The ERDF aims at strengthening economic and social cohesion in the European Union. In total the ERDF had a budget of Euro 201bn

\footnotetext{
${ }^{2}$ Recent empirical work highlights the importance of heterogeneity of firms for the explanation of income inequality in a region, see Faggio et al. (2010).
} 
for the period between 2007-2013. As all these programs are matching funds the actual amount spent has to be doubled. Technology policies are a major pillar of the ERDF that, by subsidizing firms' investments, try to move countries closer to the technological frontier. In particular, the program tries to foster investment of firms in the target region in advanced technologies, thereby improving the average quality of the physical capital stock in the target region. ${ }^{3}$ Empirical evidence for a success of the technological targeting of the measures, in the sense of an improvement of the average quality of the firms' physical capital is however missing.

Our calibrated model replicates, apart from a set of standard stylized facts about Macroeconomic and Market Dynamics, in the bench-mark case without (targeted) policies the non-convergence of regions at the bottom of the percapita income distribution as we have been observing it in Europe during the last two decades. Moreover, it captures the pattern of the evolution of the within income distribution of the wealthiest and the worst off countries and the observation that inequality is larger in the low income countries. Finally, the model also matches empirical observations about the effect of labor market flexibility on output and inequality.

We apply technology oriented policies to the lagging low-tech regions under different scenarios of labor market flexibility and are able to identify a set of results with respect to the convergence of regions and the effect on between and within regional income distribution. The technology policies that are analyzed are differentiated along their effectiveness in incentivizing firms to actually purchase investment goods from the technological frontier. A non-targeted policy results in firms not purchasing latest technology which changes as the policy becomes more targeted. Our main findings can be summarized as follows:

1. Under an inflexible labor market in the low technology region all technology policies have positive impact on the dynamics of total output in the economy. For a non-targeted policy the effect is positive in the high technology region and also positive, but weaker, in the low technology region. For sufficiently strongly targeted policies the effect is positive in the low technology region, but negative in the high technology region.

\footnotetext{
${ }^{3}$ For illustrative purposes we sketch an example highlighting what we have in mind when analyzing policies in our agent-based macroeconomic model. Here, a Portuguese firm with about 500 employees received investment subsidies to improve on the quality of its capital stock. The firm extracts ore and produces copper, lead and zinc concentrates. With the funds it modernized its infrastructure to boost extraction of copper ore by constructing new galleries to expand access to the ore, and upgraded the plant's processing operations that included facilities to wash the rock, treat and recycle water, and process waste material. Source: http ://ec.europa.eu/regionalpolicy/projects/stories/indexde.cfm
} 
2. All technology policies reduce the overall income inequality in the economy. For a non-targeted policy inequality is persistently reduced only in the high technology region. A sufficiently strongly targeted policy reduces inequality in the low technology region but makes the income distribution less equal in the high technology region.

3. The effects of the technology policies on output in the high technology region is identical under the inflexible and flexible labor market scenario. The (positive) effects on output in the low technology region is substantially stronger under a flexible labor market.

4. If the labor market in the low technology region is flexible, the nontargeted policy reduces intra-regional income inequality in both regions, whereas (strongly) targeted policies increase inequality in both regions. Effects on inequality are much stronger in the high technology region than in the low technology region. Overall inequality in the economy is reduced for all policies.

While stating these results at this point only, we will turn to an in-depth analysis of the economic mechanisms underlying these findings in sections 4.3 and the following. There, it will be shown how the various policies spark investment decisions of firms leading to wage and price reactions that result in shifts in the relative demand for goods that distinct firms equipped with particular technologies in the regions and within the regions can serve.

Our work is related to several streams of literature. The most important ones are (i) the work on the relationship between inequality and growth, (ii) the (mostly empirical) analyses of the effectiveness of European cohesion policies and (iii) the literature on agent-based macroeconomic modeling.

The literature on the relationship between inequality and growth dates back to Kuznets (1955) who argued for an inverted U-shaped relationship. Initial work modeling the inequality and growth nexus (see Aghion et al. (1999) for a survey) has argued along three different streams why inequality would foster growth. Firstly, if investments are linked to savings, and richer households have a larger propensity to save, more income inequality should be promoting growth through higher investments. Secondly, with investments being characterized by considerable sunk costs, it needs large investors to make capital accumulation happen at all, and thirdly the trade-off between equity and efficiency might be rooted in the incentives for workers. An egalitarian income distribution, so the argument goes, might discourage workers from making further efforts to climb up the income ladder.

Previously, empirical studies on the link between inequality and growth have relied on cross-country growth regressions with inequality as an ex- 
planatory variable (see, e.g. Campano and Salvatore (2006) for a survey). All these studies have provided a fairly robust body of evidence in favor of a negative relationship between income inequality and growth. As better data on income distributions and for a longer time span has become available, however, evidence seems to have shifted suggesting a positive correlation between income inequality and growth. In particular, the negative correlation seems to disappear if analyses are based on panel techniques as argued by de Dominicis et al. (2008) in a meta-analysis on existing empirical studies on income inequality and growth.

It occurs that existing studies in this strand of the literature have not looked into the interaction of technology adoption of firms and learning processes of workers to run these technologies, which eventually increases their productivity and wages. Introspection of such a channel requires heterogeneous agents on the firm and worker side which is typically beyond standard economic frameworks. It also requires to let aggregation processes through the interaction of agents work themselves out, without restricting the outcome by imposing an equilibrium condition on the model. In an agent-based framework, as we propose it, none of these restrictions apply.

Empirical work on the effectiveness of European cohesion policies finds mixed results. Studies taking a national perspective, such as Beugelsdijk and Eijffinger (2005) detect positive effects of the Structural Funds Program on GDP growth, or at least conditionally positive effects (Ederveen et al. (2006)) meaning that growth rates rise for countries with good institutions. For studies using disaggregated regional data, the findings with respect to the growth effects are inconclusive. One of the earliest attempts to evaluate the role of the Structural Funds Programme can be found in Boldrin and Canova (2001). They analyzed NUTS 2 data for 221 regions for the years 1980 to 1996, finding that disparities between regions were neither growing nor decreasing, and that EU policies have little relationship with fostering growth. Contrarily, also using sub-national data, Cappelen et al. (2003), for example, find positive growth effects. Ramajo et al. (2008) provide evidence for spatial convergence clubs in Europe, and faster conditional convergence in relative income of cohesion-fund countries, i.e. Ireland, Greece, Portugal, and Spain. Finally, Becker et al. (2010) detect positive growth effects for so-called Objective 1 transfers within the structural program but no effects on regional employment. In a follow up, Becker et al. (2013) show that only regions with sufficient human capital and good-enough institutions are able to turn the transfers into higher per capita income growth and investment.

Reasons for the differing findings may be that the data employed refers to various levels of disaggregation, and that some studies look into the overall effect of the EU funding while others evaluated more specific programs. 
We believe that our simulation based approach to evaluating these policies is complementary to these empirical studies. It allows us to look into the effectiveness of policies under different time-horizons, let's us analyze outcome variables for which data very often does not exist, and perhaps, most importantly, allows for an investigation of the economic mechanisms underlying the policy outcomes. Finally, our setting allows to carry out counter factual policy experiments, thereby evaluating policy proposals without actually implementing them.

In the last ten years a number of closed macroeconomic models using an agent-based approach have been developed (see, e.g., Gintis (2007); Dosi et al. (2010); Delli Gatti et al. (2010); Ashraf et al. (2011); Raberto et al. (2012); Wolf et al. (2012)). Several of these agent-based macroeconomic models have shown the importance of the approach for economic policy design. For example, the effect of labor market integration policies on the convergence of regions has been analyzed by Dawid et al. (2012a) and in Dawid et al. (2014) the effectiveness of human capital and technology policies as instruments of cohesion policy have been compared. Dosi et al. (2010) have looked into the (long run) effects of policies aiming at the strengthening of demand and of policies facilitating the speed of technological change as well the interaction of these polices. Monetary policies are addressed in Ashraf et al. (2013) or Arifovic et al. (2012), whereas regulatory issues relating to credit and financial markets have been analyzed by Delli Gatti et al. (2010) or Ashraf et al. (2011) within agent-based macroeconomic models. A distinctive feature of our approach relative to existing agent-based macroeconomic models is that it jointly features a spatial dimension and technology adoption by firms which is complementary to an evolving stock of specific skills within a firm.

In section 2 we will outlay what as we argue are some of the characterizing features of European economies with respect to convergence and income inequality. The following section 3 introduces the model. Section 4 starts with a description and motivation of the policy treatments. We continue by showing and analyzing the simulation output for a baseline model without policy intervention to which we then relate the effects arising from the policy analysis. Section 5 concludes.

\section{Inequality and convergence in Europe}

To which extent did European economies converge and how has income inequality evolved in these countries? We try to investigate this question by descriptively analyzing per capita incomes for 24 countries of the European 
Union. ${ }^{4}$ In 1989 the iron curtain started to fall. Eventually it implied that economies became more integrated. Product markets opened up and firms' access in lagging countries to latest technologies improved significantly. It occurs to us that the early nineties are a good starting point to look into economic convergence of the countries having been on one or the other side of the iron curtain.

Sorting countries along their GDP per capita in 1990, it turns out that Austria, Belgium, Denmark, Germany, The Netherlands, and Sweden made up the upper quartile with an average per capita income in US dollars (as of 2005 prices) of about 27.000 in 1990 (see figure 2 panel (a)). In these countries per capita income steadily increased since then to an average of about 36.000 US dollars in the year 2009. Countries in the lower quartile of the per capita income distribution (as of 1990) which happen to be all countries from the other side of the iron curtain (Bulgaria, Estonia, Hungary, Poland, Romania, and Slovakia) had an average per capita income of less than 10.000 US dollar. These countries grew in the upcoming 20 years but could by no means close or even diminish the gap with respect to the countries at the frontier. A third group of countries from Southern Europe (Greece, Italy, Portugal and Spain), in which we are mainly interested here because they feature less flexible labor markets as compared to the rest of the European countries, exhibit per capita incomes somewhere in the middle of the other two groups. Again, we do not observe a catching up process to the frontier.

How did these groups of economies fare in terms of income inequality? Panel (b) of figure 2 tries to give some insight although it has to be acknowledged that comparable and also reliable time series data on income distributions are hard to come by. Typically, Gini coefficients are calculated on the basis of in-comparable income sources, the data sources itself are not always of high quality, and representativeness is an open question. We restrict ourselves to data based on disposable income because it covers for the countries under investigation here the largest time span. The calculation of the means of the Gini coefficients for the three groups of countries excludes Romania as no comparable data occurs to be available.

After an initial spike mainly driven by the unifying Germany, high income countries have had rather stable income distributions with Gini coefficients of slightly more than 0.25 . Simultaneously we observe a marked increase in the

\footnotetext{
${ }^{4}$ We excluded four of the 28 members of the EU for the following reasons. Data on Croatia for the first years of the 90's is not available as it fought a war of secession with former Yugoslavia after having declared independence in 1991. Luxemburg has been excluded from the analysis as it constitutes an outlier, possibly because of its peculiar tax policy to attract foreign capital. Finally, no GDP data is available for Latvia and Lithuania for the year 1990 .
} 
average of the Gini coefficients of the low income countries which leveled off during the second part of the nineties but increased again in the second half of the last decade. Throughout the considered time period the Gini coefficients for the country groups with low per capita incomes indicate a much more unequal distribution compared to the high income countries. The countries from Southern Europe, which combine per capita income between the other two groups with inflexible labor markets, feature income distributions with even higher inequality than the low income countries.

In the remainder we will present an agent-based macroeconomic model which is able to replicate these developments. We will then use the framework to do policy analysis by studying subsidy schemes for firms' investments and their effect on the convergence of regions and the within regional income distribution.

\section{The Model}

\subsection{Overall Structure}

The Eurace@Unibi model describes an economy containing labor, an investment and a consumption goods sector, and a financial and a credit market in a regional context. Capital good firms provide investment goods of different vintages and productivities. Consumption good firms combine this capital and labor of varying degrees of general and specific skills to produce a consumption good that households purchase. Households' saved income goes into the credit and financial markets through which it is channeled to firms financing the production of goods. Due to space constraint we will in this section only describe the main aspects of the model, which are crucial for the understanding of the results discussed below.A detailed description of the entire model is provided in Dawid et al. (2012b).

Capital goods of different quality are provided by capital goods producers with infinite supply. The technological frontier (i.e. the quality of the best currently available capital good) improves over time, where technological change is driven by a stochastic (innovation) process. Firms in the consumption goods sector use capital goods combined with labor input to produce consumption goods. The labor market is populated with workers that have a finite number of general skill levels and acquire specific skills on the job, which they need to fully exploit the technological advantages of the capital employed in the production process. Every time when consumption goods producers invest in new capital goods they decide which quality of capital goods to select, thereby determining the speed by which new technologies 


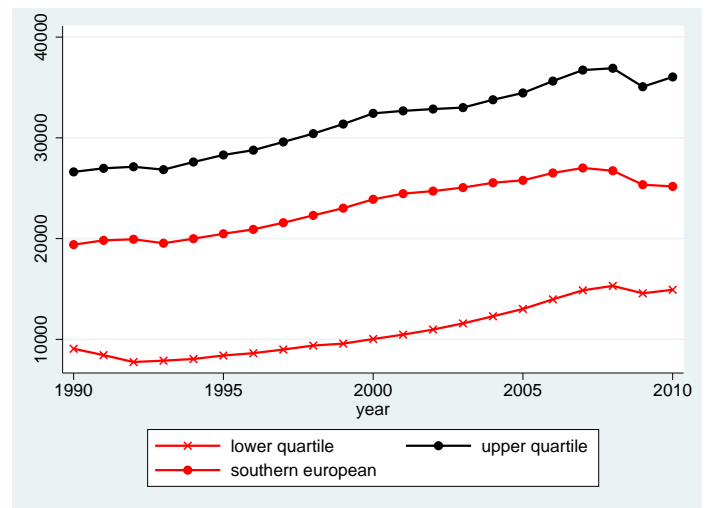

(a)

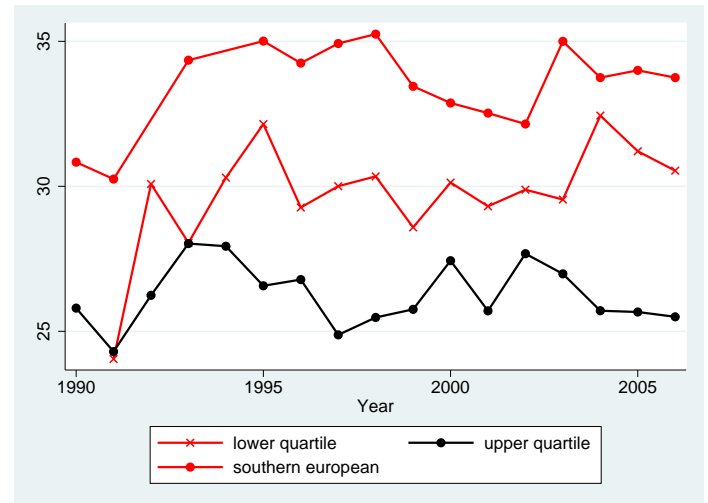

(b)

Figure 1: (a) Mean GDP per capita at 2005 constant prices (US dollars) of European countries in upper and lower quartile of GDP per capita distribution as of 1990, and for Southern European countries. Data source: Penn World Tables; (b) Mean of Gini coefficients based on disposable income of countries in upper and lower quartile of GDP per capita distribution (as of 1990), and for Southern European countries. Data source: World Income Inequality Database, United Nations University - WIDER World Institute for Development Economics Research; countries included in upper quartile are Austria, Belgium, Denmark, Germany, Netherlands, and Sweden; countries included in lower quartile are Bulgaria, Estonia, Hungary, Poland, Romania (not in mean for Gini), and Slovakia; Southern European countries are Greece, Italy, Portugal, and Spain. 
spread in the economy. Consumption goods are sold at local market platforms (called malls), where firms store and offer their products and consumers come to buy goods at posted prices. Labor market interaction is described by a simple multi-round search-and-matching procedure where firms post vacancies, searching workers apply, firms make offers and workers accept/reject. Wages of workers are determined, on the one hand, by the expectation the employer has at the time of hiring about the level of specific skills of the worker, and, on the other hand, by a base wage variable, which is influenced by the (past) tightness of the labor market and determines the overall level of wages paid by a particular employer. Banks collect deposits from households and firms and give credits to firms. The interest that firms have to pay on the amount of their loan depends on the financial situation of the firm, and the amount of the loan might be restricted by the bank's liquidity and risk exposure. There is a financial market where shares of a single asset are traded, namely an index bond containing all firms in the economy. The dividend paid by each share at a certain point in time is determined by the sum of the dividends currently paid by all firms. The central bank provides standing facilities for the banks at a given base rate, pays interest on banks' overnight deposits and might provide fiat money to the government.

Firms that are not able to pay the financial commitments declare illiquidity. Furthermore, if at the end of the production cycle the firm has negative net worth, the firm is insolvent and insolvency bankruptcy is declared. In both cases it goes out of business, stops all productive activities and all employees loose their jobs. The firm writes off a fraction of its debt with all banks with which it has a loan and stays idle for a certain period before it becomes active again.

The spatial extensions of the markets differ. The capital goods market is global meaning that firms in all regions buy from the same global capital good producer and therefore have access to the same technologies. On the consumption goods market demand is determined locally in the sense that all consumers buy at the local mall located in their region, but supply is global because every firm might sell its products in all regional markets of the economy. Labor markets are characterized by spatial frictions determined by commuting costs that arise if workers accept jobs outside their own region. It is assumed that firms have access to all banks in the economy and, therefore, credit markets operate globally.

The choice of the decision rules in the Eurace@Unibi model is based on a systematic attempt to incorporate rules that resemble empirically observable behavior documented in the relevant literature. Concerning households, this means that for example empirically identified saving rules are used and purchasing choices are described using models from the Marketing litera- 
ture with strong empirical support. With respect to firm behavior we follow the 'Management Science Approach', which aims at implementing relatively simple decision rules that match standard procedures of real world firms as described in the corresponding management literature. A more extensive discussion of the Management Science approach can be found in Dawid and Harting (2012).

Agent actions can be time-driven or event-based, where the former can follow either subjective or objective time schedules. Furthermore, the economic activities take place on a hierarchy of time-scales: yearly, monthly, weekly and daily activities all take place following calendar-time or subjective agenttime. Agents are activated asynchronously according to their subjective time schedules that is anchored on an individual activation day. These activation days are uniformly randomly distributed among the agents at the start of the simulation, but may change endogenously (e.g., when a household gets re-employed, its subjective month gets synchronized with the activation day of its employer due to wage payments). This modeling approach is supposed to capture the decentralized and typically asynchronous nature of decision making processes and activities of economic agents.

\subsection{Agents, Markets, and Decisions}

\subsubsection{Output Decision and Production}

Consumption goods producers need physical capital and labor for production. A firm $i$ has a capital stock $K_{i, t}$ that is composed of different vintages $v$ with $v=1, \ldots, V_{t}$, where $V_{t}$ denotes the number of available vintages a time $t$. The accumulation of physical capital by a consumption goods producer follows

$$
K_{i, t+1}^{v}=(1-\delta) K_{i, t}^{v}+I_{i, t}^{v}
$$

where $\delta$ is the depreciation rate and $I_{i, t}^{v} \geq 0$ is the gross investment in vintage $v$.

The production technology in the consumption goods sector is represented by a Leontief type production function with complementarities between the qualities of the different vintages of the investment good and the specific skill level of employees for using these vintages. Vintages are deployed for production in descending order by using the best vintage first. For each vintage the effective productivity is determined by the minimum of its productivity and the average level of relevant specific skills of the workers. Accordingly, output for a consumption goods producer is given by

$$
Q_{i, t}=\sum_{v=1}^{V_{t}} \min \left[K_{i, t}^{v}, \max \left[0, L_{i, t}-\sum_{k=v+1}^{V_{t}} K_{i, t}^{k}\right]\right] \cdot \min \left[A^{v}, B_{i, t}\right],
$$


where $A^{v}$ is the productivity of vintage $v$ and $B_{i, t}$ denotes the average specific skill level in firms as explained in more detail in Section 3.2.3. The fact that the considered production function takes into account the vintage structure of the capital stock and that firms select among different available vintages enables us to capture the effect of workers' skills on the incentives of firms to invest into new technologies (see Section 3.2.4).

Once every month each firm determines the quantities to be produced and delivered to each regional mall the firm is serving. Actual demand for the product of a firm in a given mall and a given month is stochastic (see below) and there are stock-out costs, because consumers intending to buy the product of a firm move on to buy from a different producer in case the firm's stock at the mall is empty. Therefore, the firm faces a production planning problem with stochastic demand and stock-out cost. The simplest standard heuristic used in the corresponding Operations Management literature prescribes to generate an estimation of the distribution of demand and then choose the planned stock level after delivery such that the (estimated) stock-out probability during the following month equals a given parameter value (which is influenced by stock-out costs, inventory costs and risk attitude of the firm (see e.g. Silver et al. (1998)). Firms in the Eurace@Unibi model follow this simple heuristic, thereby generating a target production quantity for the considered month. Based on the target production quantity the firm determines the desired input quantities of physical capital and labor. Realizing this production plan might induce the need to buy new physical capital, hire new labor or to obtain additional credit. While there is infinite supply of physical capital the firm might be rationed on the labor and credit market. In this case the firm accordingly adjusts its production quantity downwards.

\subsubsection{Pricing Decision}

Consumption goods producers set the price of their products once a year which is consistent with empirical observations (see, e.g., Fabiani et al., 2006). The pricing rule is inspired by the price setting described in Nagle and Hogan (2006, ch.7), a standard volume on strategic pricing in the Managerial literature. Firms seek for a profit-maximizing price taking into account the trade-off between price, sales and costs.

To obtain an indication of the effect of price changes on sales the consumption goods producers carry out simulated purchase surveys (see Nagle and Hogan, 2006, pp. 300). A representative sample of households is asked to compare a firm's product with the set of the currently available rival products for a range of prices. Households' answers are based on the same 
decision rules they use for their real purchasing decisions. Based on the resulting demand estimations and cost considerations firms choose the price which maximizes their expected discounted profit stream over their planing horizons.

\subsubsection{Adjustment of Specific Skills of Workers}

Each worker $h$ has two dimensions of human capital endowments namely an exogenously given general skill level $b_{h}^{\text {gen }}$ and an endogenously increasing specific skill level $b_{h, t}$. General skills can be interpreted as formal qualification or general embodied abilities while specific skills are experiences or abilities obtained on-the-job reflecting the productivity of each worker. For simplicity it is assumed that only two general skill levels exist $b^{\text {gen }} \in\{1,2\}$, where $b^{g e n}$ refers to the general skill level. General skills are observable by firms in the hiring process while specific skills are not. They become observable during the production process. Acquisition of specific skills in the production is faster for the higher general skills. Formally, the workers increase the specific skills over time during production by a learning process. The speed of learning depends on the general skill level $b_{h}^{\text {gen }}$ of the worker $h$ and the average quality of the technology $A_{i, t}$ used by employer $i$ :

$$
b_{h, t+1}=b_{h, t}+\chi\left(b_{h}^{g e n}\right) \cdot \max \left[0, A_{i, t}-b_{h, t}\right] .
$$

Here $b_{h, t}$ are the specific skills of worker $h$ in period $t$ and $\chi\left(b_{h}^{\text {gen }}\right)$ increases with general skills $b_{h}^{\text {gen }}$ and $0<\chi\left(b_{h}^{\text {gen }}\right)<1$. Endogenizing the general skill distribution in a region would require an explicit representation of educational choices and the inclusion of an education sector, which would make the model much more complex and is beyond the scope of this paper.

\subsubsection{Technological Change}

The supply of the capital goods and the process of technological change is modeled in a very simplified stylized way, since the focus of our analysis lies on the interaction of the dynamics on the labor and consumption goods markets. There is a monopolistic capital goods firm that offers different vintages of the capital good $v=1, \ldots, V_{t}$, which differ regarding their productivity $A^{v}$, at infinite supply. This firm is therefore able to satisfy all emerging capital demand of consumption goods firms. Furthermore, the capital good is produced without input factor requirements and, in order to close the model, all revenues are channeled back into the economy by distributing them to households in the form of dividends. New vintages become available over time following a stochastic process. To avoid spurious growth effects, due 
to stochastic differences in the dynamic of the technological frontier between runs, we use the identical realization of the stochastic process governing the emergence of new vintages in all considered runs.

The pricing of the vintages is modeled as a combination of cost-based and value-based pricing, where the growth rate in the first term follows the growth rate of average labor costs and the value-based price component estimates the value that each vintage has for a reference firm whose workforce consists of the economy wide average levels for the specific skills as well as general skills.

\subsubsection{Investment and Vintage Choice}

If consumption good producers have a target output level which cannot be produced with their current capital stock, they acquire new capital. To this end, a consumption goods firm has to choose from the set of available vintages. For the decision in which vintage to invest the complementarity between specific skills and technology plays an important role: due to the inertia of the specific skill adaptation, the effective productivity of a vintage with $A^{v}>B_{i, t}$ is initially below its quality. It converges to $A^{v}$ over time as the specific skills of workers at the firm catch-up to the quality of the vintage. Therefore, the firm computes a discounted sum of estimated effective productivities over a fixed time horizon $S$. The specific skill evolution is estimated for each time step within $[t, t+S]$ using (3), where the firm inserts its average general and specific skill values. A logit choice model based on the ratio of the estimated effective productivity and price for each available vintage determines which vintage is ordered. In several parts of the Eurace@Unibi model choices of decision makers are described by logit models. These models are well suited to capture decisions where individuals try to maximize some objective function which depends on some variables common to all decision makers and are explicitly represented in the model, as well as on aspects that are idiosyncratic to each decision maker and captured in the model by a stochastic term.

\subsubsection{Labor Market Interaction}

If the current workforce of a firm is not sufficient to produce its target output, the firm posts vacancies for production workers. The wage it offers has two constituent parts. The first part is the market driven base wage $w_{i, t}^{\text {base }}$. The base wage is paid per unit of specific skill. If the firm cannot fill its vacancies and the number of unfilled vacancies exceeds some threshold $\bar{v}>0$ the firm 
raises the base wage offer by a fraction $\varphi$ to attract more workers, i.e.

$$
w_{i, t+1}^{\text {base }}=(1+\varphi) w_{i, t}^{\text {base }} .
$$

The second part is related to the specific skills. Since the specific skills represent the (maximal) productivity of the employees the wage $w_{i, t}$ is higher for higher specific skills. For each of the general-skill groups the firm $i$ offers different wages $w_{i, t, g}^{O}$ in period $t$. The wage offers are given by

$$
w_{i, t, g}^{O}=w_{i, t}^{\text {base }} \times \min \left[A_{i, t} \bar{B}_{i, t-1, g}\right]
$$

where $\bar{B}_{i, t-1, g}$ are the average specific skills of all employees with general skill $g$ in the firm. The underlying assumption of this determination of wage offers is that firms can observe general but not specific skills of job applicants. Therefore they use the average specific skills of all employees with general skill $g$ in the firm in order to estimate the specific skills of an applicant with general skill level $g$. This wage setting rule is a reduced form representation of the outcome of firm-level wage negotiations taking into account workers' expected productivity in the firm as well as workers' outside option.

An unemployed worker takes the wage offers posted by searching firms into consideration and compares them with his reservation wage $w_{h, t}^{R}$. An unemployed worker will only apply at a firm that makes a wage offer such that

$$
(1-c) w_{i, t, g}^{O}>w_{h, t}^{R}
$$

where $w_{h, t}^{R}$ denotes the reservation wage of the worker and $c \in[0,1]$ captures the commuting costs. If workers and employers are in the same region we have $c=0$. Since labor movement between European countries is still very small $5^{5}$ we assume in our policy analysis below that $c=1$, which means that commuting costs are so high that workers search only for jobs in their own region.

The level of the reservation wage is determined by the current wage if the worker is employed, and in case of an unemployed worker by his previous wage, where the reservation wage declines with the duration of unemployment. The reservation wage never falls below the level of unemployment benefits. If the unemployed worker receives one or more job offers he accepts the job offer with the highest wage offer. In case he does not receive any job offers he remains unemployed.

In case the workforce of a firm is too large relative to its target output level, the firm adjusts its number of workers, where employees with low general skills are dismissed first. Additionally, there is a small probability for

\footnotetext{
${ }^{5}$ In 2010 , only $2.8 \%$ of working-age European citizens lived in another EU member state (see European Commission (2011)).
} 
each worker-employee match to be separated in each period. This should capture job separations due to reasons not explicitly modeled.

\subsubsection{Consumption Market Interaction}

The consumption goods market is modeled as a decentralized goods market. Each local market is represented by a mall at which the consumption goods producers can offer and sell their products to their customers. While firms are free to serve all malls regardless their spatial proximity, households always choose the mall which is located in their region.

Households go shopping once a week and try to spend their entire weekly consumption budget for one good. The consumption budget is determined using a (piecewise) linear consumption rule according to the buffer-stock approach (see Carroll (1997) and Allen and Carroll (2001)). At the beginning of their shopping procedure they get information about the prices of all available goods at the mall, but they get no information about the available quantities. The decision which good to buy is described using a logit-choice model with strong empirical foundation in the Marketing literature (see e.g. Malhotra (1984)). An important parameter in this respect is the coefficient of the price of a good in the logit choice function. This parameter, denoted as $\gamma^{C}$, governs the price sensitivity of consumers and therefore the intensity of competition between the consumption good producers.

Households have a-synchronized shopping days and thus on each day of the months there is in general some shopping activity in each mall. The consumption requests for the different goods are collected by the mall and, if the total demand for one good exceeds its mall inventory level then the mall has to ration the demand. In this case the mall sets a rationing quota corresponding to the percentage of the total demand that can be satisfied with the available goods. Each household receives then the indicated percentage of the requested consumption good.

After the shopping activity rationed households may still have left over a part of their budget. Those households have the opportunity to spend the remaining budget for another good in a second shopping loop. In this case the shopping process is repeated as described above.

The production of the consumption goods firm follows a fixed time schedule with fixed production and delivery dates. Even if the mall stock is completely sold out it can only be refilled at the fixed delivery date. Consequently, all the demand that exceeds the expected value of the monthly sales plus the additional buffer cannot be satisfied. 


\subsubsection{Public Expenditures and Taxes}

The public sector is modeled in a parsimonious way. In each region the government pays the unemployment benefits, where the monthly amount an unemployed receives is determined by the last wage earned by worker and the replacement rate in the region. As discussed in more detail below, motivated by observed differences within European countries we will consider different level of these replacement rates. In addition the policy measures discussed in the next section are financed by public funds. In particular, the total amount of firm subsidies paid out under these policy measures is financed by a common fund of the economic union jointly endowed by both regions, where the contribution of each region is proportional to its GDP. This setting captures in a stylized manner the way funds like the ERDF are financed by the member countries of the European Union. The public expenditures in each region are fully financed by an income tax. In each period the government collects an income tax from households and a corporate tax from firms (if they have positive profits in that period). For simplicity it is assumed that the tax rate, denoted as $\tau_{r, t}$ for region $r$ at time $t$, is identical for both types of taxes. Governments in all regions aim at a balanced budget and adjust the tax rates over time. The adjustment process follows a backward-looking budget planning, i.e. the tax rate for the current period $t, \tau_{r, t}$, is chosen such that ex-post the tax revenue and the government spending of a previous time period are balanced. This time horizon has to be sufficiently long in order to avoid highly volatile tax rates due to short-term fluctuations in the tax basis or the government spending (here we use a time horizon of 72 months).

\subsection{Parametrization and Validation}

In order to determine the values and ranges of parameters to be used in the policy experiments we follow an approach that combines direct estimation of parameters for which empirical observations are available with an indirect calibration approach in order to establish confidence in the ability of the model to capture economic mechanisms which are relevant for real world economic dynamics. Standard constellations have been identified, where values of parameters are chosen to reflect empirical evidence whenever possible and where a large set of stylized facts can be reproduced. Furthermore, the fact that the development of the Eurace@Unibi model follows as far as possible the Management Science approach, briefly discussed above, provides empirical grounding to individual decision rules, thereby addressing the important point of empirical micro-foundations for modeled behavior. The set 
of macroeconomic stylized facts that have been reproduced by the standard constellations of the Eurace@Unibi model includes persistent growth, low positive inflation and a number of important business cycle properties: persistent fluctuations of output; pro-cyclical movement of employment, consumption and investment, where relative sizes of amplitudes qualitatively match those reported e.g. in Stock and Watson (1999), counter-cyclical movement of wages and firm mark-ups. On the industry level the model generates persistent heterogeneity in firm-size, profit rates, productivity and prices in accordance with empirical observations reported e.g. in Dosi et al. (1997). Also labor market regularities, like the Beveridge curve, are reproduced by the model with benchmark parameter constellations. The reader is referred to Dawid et al. (2012b) for a more detailed discussion of this issue. Tables with the list of parameter values used in the simulations underlying this paper are provided in the Online-Appendix.

Finally, it should be mentioned that the analysis in the next section will show that the calibrated version of the model does not only qualitatively reproduce the empirical patterns of the evolution and the relative size of per capita output in different types of economies shown in figure 2 (a), but also the patterns of income inequality measured by the Gini coefficient. In particular, the model not only reproduces that low technology regions have lower per-capita output and higher Gini coefficients than high technology regions, but also the observation that the regions with relatively inflexible labor markets are characterized by larger income inequality compared to the low tech regions with flexible labor markets, although their per capita output is higher. All these stylized facts have been reproduced although they have not been targeted in the calibration and the parameter setting has not been adjusted from the default setting described above.

\section{Policy analysis}

\subsection{Experimental set-up}

Our policy experiments are addressing convergence between an advanced and a lagging region (country) and the evolution of the distribution of income within a region in a two-region version of the model described above. Table 1 summarizes the initializations of the key variable for the two distinct regions $\mathrm{R} 1$ and R2. At time $t=0$ the quality of the capital stock in the high tech region $\mathrm{R} 1$ is set to 1.5 , and to 1.0 in the low tech region. The choice of the (adapting) specific skills corresponds initially to the quality of the capital stock. In R1 $80 \%$ of the workers have high general skills, and the 
Table 1: Initialization of capital stock and skills

\begin{tabular}{l|cc}
\hline & Region 1 (R1): high tech & Region 2 (R2): low tech \\
\hline Initial quality of capital stock & 1.5 & 1.0 \\
Initial specific skills & 1.5 & 1.0 \\
General skill distribution & $0.8 / 0.2$ & $0.2 / 0.8$ \\
\hline
\end{tabular}

remaining part has low general skills. For R2 the general skill distribution is inverted. This setting is supposed to capture in a very simple way that on average workers in the high tech region 1 adjust faster to an increase in the quality of the physical capital they are working with than workers in region 2. The technological frontier at $t=0$ is set to a quality of 1.7 and afterward grows at an annual rate of 1.8 percent. Firms in both regions may purchase an investment good of that quality, i.e. investment goods markets are integrated from the beginning of the simulation. The same holds for the consumption goods markets.

Within this setup we mimic the European Union technology policies by introducing a subsidy for investments of firms in the target region R2. The subsidy covers $20 \%$ of the expenses of the firm for the purchase of the new physical capital. In particular, we consider in our experiments four different variations of technology policies, which differ with respect to their influence on the technology choice of the firms receiving the subsidy. We define by $0 \leq$ $\alpha \leq 1$ the probability that a firm receiving a subsidy under the policy acquires the latest vintage directly on the frontier regardless of whether this would be the vintage choice according to its own vintage choice rule. With probability $1-\alpha$ the firm follows its standard vintage choice rule. In the experiments we consider the values $\alpha=0$, which is denoted as non-targeted technology policy, as well as the cases $\alpha=0.1,0.2$ and 0.3 , corresponding to an increase in the direct influence of the policy on the firms' vintage choice. The reason to consider these different policy variations is twofold. First, even if the policymaker's intention is to only subsidize firm's investments if they are of the high quality vintage type, it is in general difficult for the policymaker to determine what is exactly the frontier technology for a given firm. This makes the enforcement of the highest vintage constraint problematic and it is important to understand how crucial it is for the effect of the policy if no perfect enforcement is possible. This experimental set-up may be seen in relation to the literature that studies the role of absorptive capacity for the effectiveness of transfers. While this line of investigation has been playing a prominent role in the evaluation of aid policies (Burnside and Dollar, 2000), it has become of interest in the context of analyzing the effectiveness of EU 
funds only recently (see, e.g., Becker et al., 2013). Second, a-priori it is not clear whether it is actually useful for convergence that a policy tries to influence the vintage choice of firms in a way that they acquire high vintages that they would not have selected without external pressure. Our analysis intends to shed light on this question by comparing non-targeted with targeted subsidy policies.

The targeted and the non-targeted technology policy is studied for two labor market regimes. In one scenario we assume in both regions a relatively high wage replacement rate $(70 \%)$ and also assume that the reservation wages of unemployed workers adjust at a speed we can empirically observe in Western European countries 6 In the second scenario we analyze the effect of technology policies under the assumption that replacement rates in the lowtech region $\mathrm{R} 2$ are much lower $(55 \%)$ and reservation wages adjust much faster there. The motivation for the consideration of this second treatment is that empirically replacement rates in many of the new EU member states from Eastern Europe are much lower than in Western European countries and labor markets tend to be more flexible. ${ }^{7}$ The faster adjusting reservation wages may reflect the consequences of various labor market policies of the more recent past that aim at integrating unemployed workers more quickly into the labor market. Examples of such policies are the reduction of the duration of unemployment benefit payments to worker, tighter controls of unemployed workers' search intensity through employment agencies, or the introduction of the obligation to accept job offers that are below a worker's skills.8

For each of the considered policies 20 runs are conducted in both labor market scenarios, with each run encompassing 1400 months. For each policy the time series are pooled across labor market scenarios and the policy effects are estimated using penalized spline methods (see, e.g., Kauermann et al., 2009). More technically, the isolated effects and the interacted effects of a

\footnotetext{
${ }^{6}$ We use the findings in Burda and Mertens (2001) on wage losses of $17 \%$ after spells of unemployment in Germany assuming an average duration of 30 weeks.

${ }^{7}$ Whereas the average net replacement rates for one earner families with two children slightly increased from the beginning of the seventies starting at about $65 \%$ for two percentage points for the old EU member states, the average over the new members states of the EU declined from above $60 \%$ to about $55 \%$, recently, see van Vliet and Caminada (2012).

'In its 2007 Employment Outlook (OECD, 2007) the OECD surveys the various measures that have been taken by countries to activate the unemployed concluding that efforts to speed up re-employment are on a rise.
} 
policy are evaluated by estimating the equation

$$
\begin{gathered}
Y_{t, p, i}=s(t)+I_{[p(L M)=1]} s_{\text {Flex }}(t)+I_{[p(\text { Tech })=1]} s_{\text {Tech }}(t)+I_{[p(L M)=p(\text { Tech })=1]} s_{\text {Int }}(t) \\
+\eta_{i}^{0}+\eta_{i}^{1} t+\varepsilon_{t, p, i}
\end{gathered}
$$

where $Y_{t, p, i}$ is the outcome variable at iteration $t$, for policy $p$, and run $i$. The baseline spline is $s(t)$ to which the policy splines are added with dummy variables $I$ indicating if the policy is turned on or off. The linear term involving $\eta_{i}^{0}$ and $\eta_{i}^{1}$ captures run-specific random effects and $\varepsilon_{t, p, i}$ is the error term. The standard deviation of the spline estimates will also be plotted in the figures in order to illustrate significance of the different policy effects over time. The effect over time of the policy in the scenario with an inflexible labor market in region $\mathrm{R} 2$ is given by $s_{\text {Tech }}(t)$. The difference in the policy effect between the two labor market scenarios is captured in $s_{\text {Int }}(t)$, which implies that the policy effect under a flexible labor market can be seen by considering $s_{\text {Tech }}(t)+s_{\text {Int }}(t)$. Finally, $s_{\text {Flex }}(t)$ gives an estimate of the effect of increased labor market flexibility on the considered variable in the base scenario without policy. 9

\subsection{The baseline scenario}

We proceed by showing that our agent-based macroeconomic model is able to replicate the stylized developments in terms of per capita income between regions and income inequality within regions as outlined before. Once, the behavior of the baseline model is explained we will go into the policy analysis applying the technology policies to our model, and augmenting it with an analysis of the technology effects under different schemes of reservation wage flexibility.

Figure (2) shows output per capita in the left panel and Gini coefficients -our measure for income inequality - in the right panel for the advanced (black line) and lagging regions (red line) in the baseline scenario where labor markets in $\mathrm{R} 2$ are inflexible. The lagging region 2 never accomplished to close the gap in terms of per capita income to region 1 . After about 120 years income in region 1 is seven times higher where income in region 2 has only tripled. Initially, this process of income divergence between regions is

\footnotetext{
${ }^{9}$ All figures are based on estimations using the $\mathrm{R}$ function gamm() from the package mgcv (see e.g. Wood (2011)). Although residuals in our estimation show some autocorrelation we abstain from estimating a computationally much more intensive and less stable model with $\mathrm{AR}(\mathrm{p})$ structure of the noise terms. Krivobokova and Kauermann (2007) have shown that the spline estimations are robust with respect to mis-specified correlation structures, and therefore no qualitative changes of our results should be expected even if a model with more elaborated correlation structure would be used.
} 


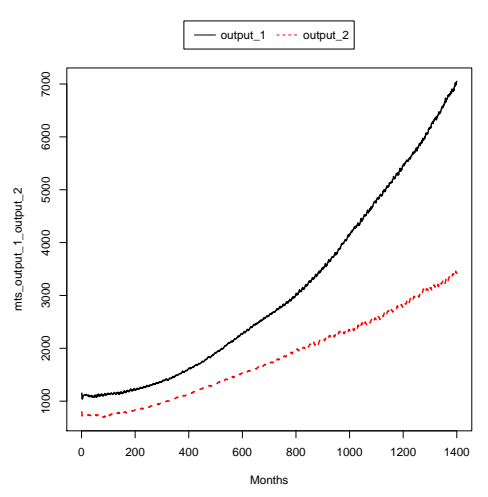

(a)

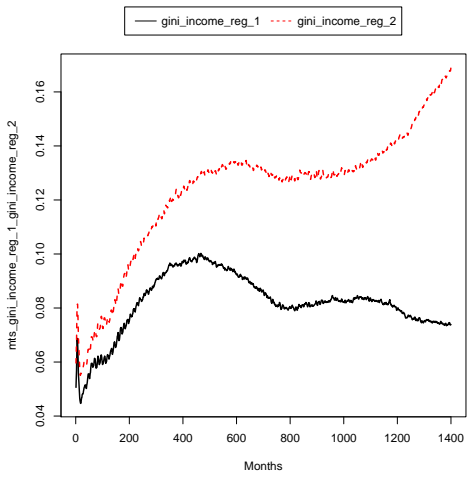

(b)

Figure 2: Dynamics of output (a) and Gini coefficient (b) in both regions

accompanied by an increasing income inequality within regions. However, income inequality starts declining in region 1 after about 40 years. Over the whole time span the distributions of incomes within regions feature higher inequality in the low income region. All these patterns are in accordance with the empirical evidence as presented in figure 2, where we interpret region 2 as a representative of the group of southern European countries with relatively inflexible labor markets.

What stands behind these developments can be explained with the help of Figure 3. Key for understanding the non-convergence is the inability of firms in region 2 to become competitive with firms in region 1. Plotting goods prices of region 1 relative to those of region 2 highlights that firms in region 2 have to charge higher prices on average which feeds back on that region's overall demand as households will prefer to purchase the less expensive goods. Firms in region 2 charge higher prices as they face higher unit labor costs over the whole time span considered (panel b).

That firms in region 2 have on average higher unit labor costs than firms in region 1 is due to an intricate wage process taking place in region 2. Region 2 is characterized by two groups of firms. On the one hand, we have firms that employ high quality capital close to the technological frontier. These firms have capital endowments very similar to the firms in the advanced region 1. They are able to pay relatively high wages in line with their workers' above average productivity. On the other hand, we have firms in region 2 which are technologically lagging behind but try to hire workers from the same (regional or country specific) labor market. The relatively high wages paid by technologically advanced firms in region 2 push up workers' reservation wages. Once a worker employed by one of these well performing firms loses 


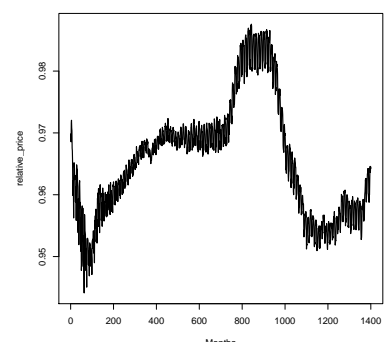

(a)

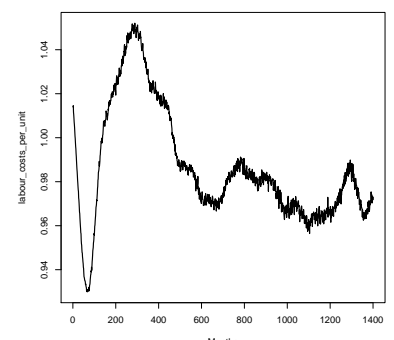

(b)

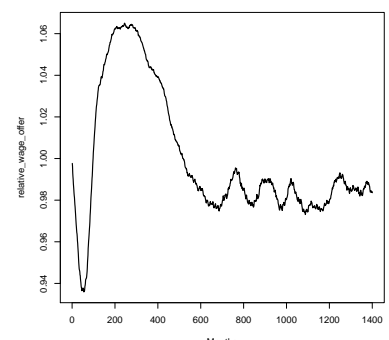

(c)

Figure 3: relative prices $\mathrm{R} 1$ to $\mathrm{R} 2$ (a), relative unit labor costs $\mathrm{R} 1$ to $\mathrm{R} 2$ (b), relative wage offer $(\mathrm{c})$

his job, he will have a reservation wage reflecting his former wage paid. This implies for the lagging firms that they have to increase their base wage offers to successfully bid for workers. Consequently, their labor costs increase, and as they do not have high quality capital, higher labor costs cannot be covered by higher productivity. Also, in spite of the relatively high base wage offers the low-technology firms pay, they are not able to attract at a large scale workers with high general and specific skills. This in turn keeps their incentives to invest in advanced technologies low and the strong heterogeneity of firms in region 2 is preserved and actually grows over time. Panels (a) to (c) of Figure 4 illustrate this mechanism by devising the ratios of several key variables between the average value of firms operating with technologies above the median in region 2 and the average value of firms operating with technologies below the median. Panel (a) demonstrates that the low-tech firms indeed pay higher base wages and therefore charge higher prices (Panel (b)). The persistent substantial difference in specific skills of workers at hightech relative to low-tech firms in region 2 is demonstrated in Panel (c). A similar picture would emerge if general rather than specific skills would be considered, but we abstain from showing this figure here.

\subsection{Effects of Technology Policies}

In this subsection we discuss the implications of the different technology policies for output and (inter- and intra-regional) inequality under inflexible labor markets in the target region. The case of flexible labor markets will be covered in the following subsection. We structure our analysis such that we state several main qualitative insights obtained from our simulation experiments as 'Results'. Then for each of these results we provide the statistical analysis backing the result as well as a discussion of the economic mecha- 


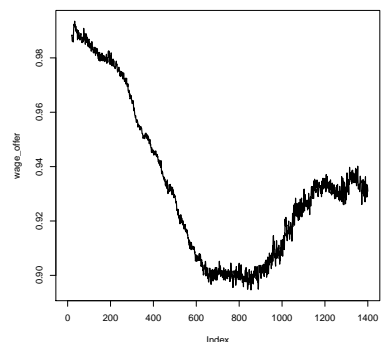

(a)

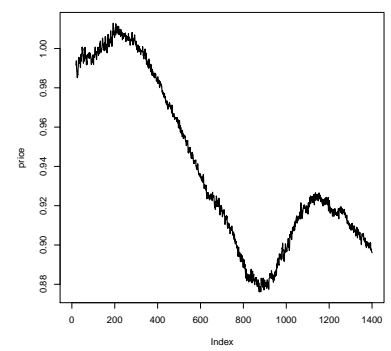

(b)

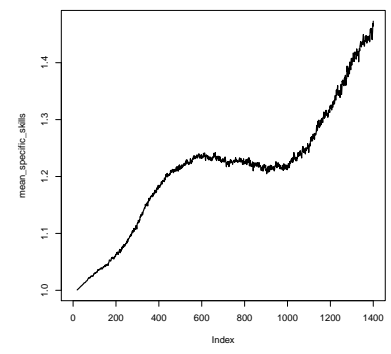

(c)

Figure 4: relative wage offers (high-tech/low-tech firms) in R2 (a), relative prices in R2 (b), relative level of specific skills in R2 (c)

nisms that are responsible for the observed finding.

Result 1: Under an inflexible labor market in the low-tech region all technology policies have positive impact on the dynamics of total output in the economy. For a non-targeted policy the effect is positive in the high technology region and also positive, but weaker, in the low technology region. For sufficiently strongly targeted policies the effect is positive in the low technology region, but negative in the high technology region.

Evidence for the observations in Result 1 is provided in figures 5 (a)-(c). The first panel shows the effect of the various technology policies on global output (adding up regions 1 and 2) for our default scenario, whereas the two other panels give the effects in each of the two regions. This figure, as well as most of the following figures in this section, relies on the penalized spline approach discussed above to show the dynamic effects of the different policies. Solid lines show the mean effect and dashed lines indicate one standard deviation bands. The global output effect is positive even for a non-targeted policy but clearly trumped by all variants of targeted policies. A similar qualitative picture arises for the target region $\mathrm{R} 2$, however for the high-tech region $\mathrm{R} 1$ the implications of the policy change not only quantitatively but also qualitatively as we move from a non-targeted to a (strongly) targeted technology policy.

To understand the economic mechanisms for these policy effects we first focus on the non-targeted policy. The primary effect of the policy is to reduce marginal investment costs of firms in region 2. Intuitively this should lead to a reduction of unit costs and prices of firms in region 2 relative to those 


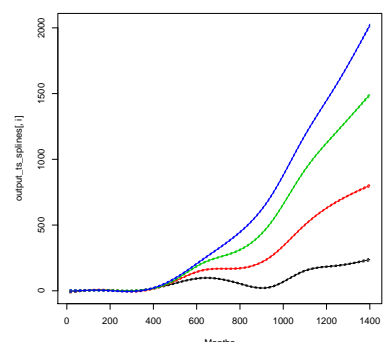

(a)

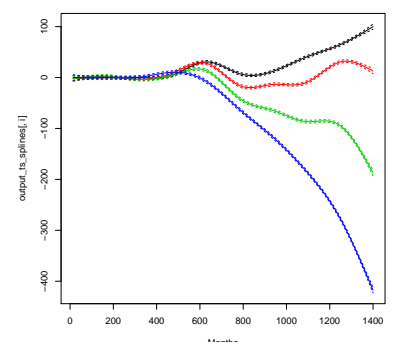

(b)

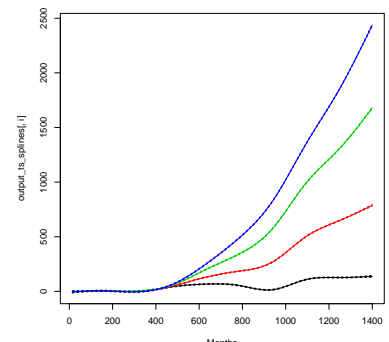

(c)

Figure 5: Effect of the different technology policies on global output (a), output in region 1 (b) and output in region 2 (c) (color code: $\alpha=0$ : black, $\alpha=0.1$ : red, $\alpha=0.2$ : green, $\alpha=0.3$ : blue).

in region 1, thereby improving the competitiveness of firms in region 2 and shifting demand towards firms from that region. Based on this reasoning it should be expected that the policy has positive effects only or at least primarily in region 2. In panel (a) of Figure 6 we depict the effect of the policy on the ratio on output produced in region 1 and region 2 . It can be seen that the positive effect of the policy is indeed slightly larger in the target region and hence convergence is fostered, but the effect is very minor. The reason for this small effect is that the policy does not lead to a substantial increase in competitiveness of firms in region 2. Only initially the policy induces an increase of the ratio of prices charged by region 1 firms to that of region 2 firms. In the middle and long run the policy reduces this relative price making firms in region 1 even more competitive (see Figure 6 (b)). To understand this effect the dynamics on the labor market have to be considered. As can be seen in panel (c) of Figure 6 the policy leads to a substantial increase of the base wage offers of firms in region 2 relative to that in region 1 . Since the base wage determines the labor costs per productivity unit of a worker this increase contributes to an increase of unit costs in region 2 relative to region 1. Considering our findings with respect to the effects of the policy on relative prices we can conclude that this indirect wage effect of the introduction of the subsidy actually outweighs the direct effect of the policy on investment costs. As will become clear when we study the effects of the policy under a more flexible labor market in region 2, the strong heterogeneity of firms and workers in region 2 that emerges in the inflexible labor market setting (see our discussion of the baseline scenario above) is a crucial factor for this ambivalent policy effect. In particular, the low tech firms in region 2, face problems to hire additional workers when they try to expand their production 


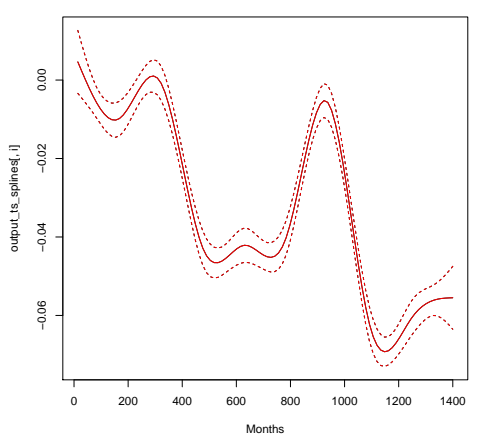

(a)

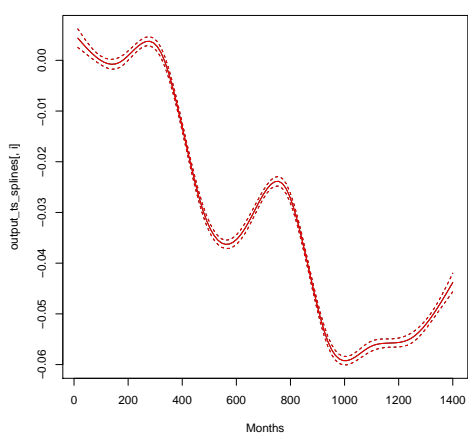

(c)

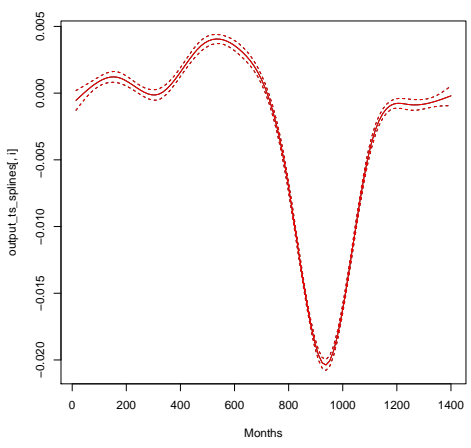

(b)

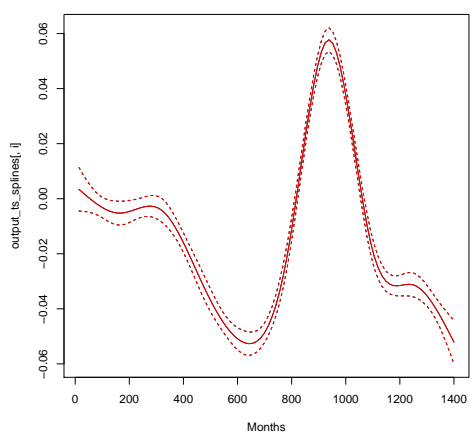

(d)

Figure 6: Effect of the non-targeted technology policy on relative output (a), relative prices (b) relative base wage offer (c) and relative quality of capital stock (d).

after the introduction of the non-targeted subsidy, which further drives up their base wage offers. Finally, in 6 (d) the effect of the policy on the ratio of the average quality of capital stocks of firms in region 1 relative to region 2 is considered. Here, the policy has no significant positive effect on the technological convergence of region 2 firms toward those in region 1 . The small positive effect with respect to output convergence is fully driven by the reduction of relative (investment) costs.

Having discussed the mechanisms underlying the effects of a non-targeted technology policy we now consider how these effects change if the policy is able to induce a certain fraction of firms in region 2 to adopt the frontier technology. Figure 5 clearly shows that such targeted policies indeed can foster convergence of the two regions in terms of real output. The effect of output in the target region 2 is strongly positively affected whereas the 
output produced in region 1 is decreased due to the policy.

When considering the comparison of effects across the different policies it should be kept in mind that in our model tax rates in the two regions are dynamically adjusted such that public expenditures are covered by taxes. In this sense all policies are self-financed and the differences are not due to differences in inflow of public funds (e.g. due to credits from other regions or supply of funds by the central bank).

The main reason for the positive convergence effects with respect to output of the targeted technology policies is that, other than for the non-targeted policies, a reduction of the technological gap between the two regions is achieved. Figure 7 (a) shows that under targeted policies the ratio between the average quality of physical capital in region 1 to that in region 2 declines significantly, where the effect is stronger the more targeted the policy is. Clearly, this effect is driven by the vintage choice of firms in region 2 . The increased productivity of these firms, however, also has a positive second order effect for region 2, because it allows firms to expand production without hiring new workers. This reduces the pressure on the labor market, which was the main reason for the ambiguous effects of the non-targeted policy. Panel (b) of Figure 7 shows that at least for large values of $\alpha$ the targeted technology policies positively affect the ratio of base wage offers in the two regions. Considering the effect in each of the regions (not shown here) it becomes clear that this observation is driven by a reduction of base wage offers in region 2 due to the policy. For only weakly targeted policies implications of the productivity increase on base-wage offers is not sufficiently large to outweigh the negative forces described for the non-targeted policy, and hence the overall effect on relative base-wage offers is still slightly negative.

Together the positive effect of the targeted policies on productivity in region 2 and the negative effects on labor costs leads to an increase in competitiveness of firms in region 2, which is expressed by an increase of the relative price of the good charged by firms in region 1 relative to those in region 2 and a simultaneous catching-up of firms in region 2 with respect to the mark-ups they can charge (see panels (c) and (d) in Figure 7). This explains the partial shift of demand, and therefore production, from region 1 firms to region 2 firms. The positive overall effects of the targeted policies is also mainly driven by the reduction in unit costs of production in region 2 , however it should also be taken into account that in a closed model like ours the increased investment, that is induced by the policies, leads to an increase in income of households (since they own the investment good producer) and thereby strengthens demand.

We now turn to the effect of the considered technology policies on overall inequality and the intra-regional distribution of income. As before we rely 


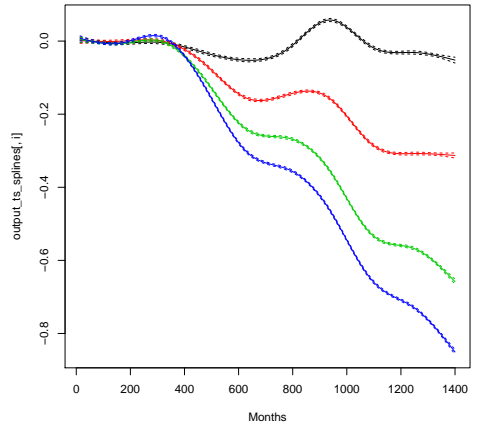

(a)

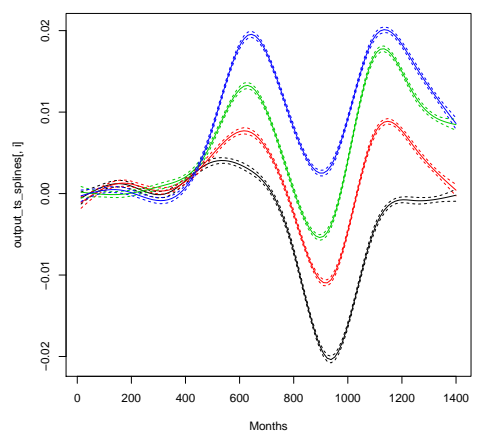

(c)

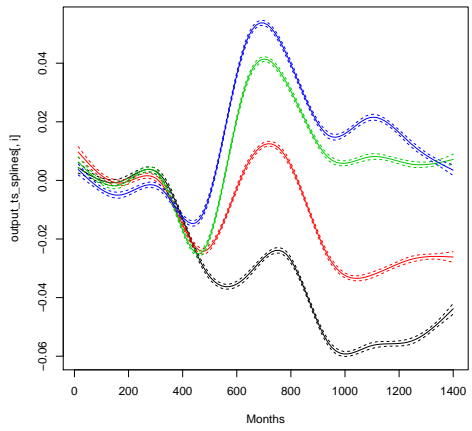

(b)

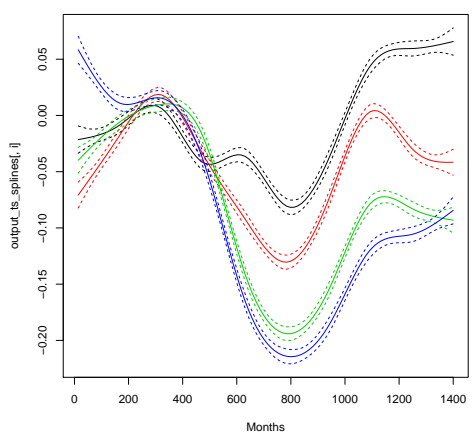

(d)

Figure 7: Effect of the different technology policies on relative quality of technology in the two regions (a), relative base-wage offers (b), relative prices (c), and relative mark-ups (d).

on the Gini coefficient of current income of households in order to measure income inequality. Using this indicator we obtain the following qualitative insight.

Result 2: All technology policies reduce the overall income inequality in the economy. For a non-targeted policy inequality is persistently reduced only in the high technology region. A sufficiently strongly targeted policy reduces inequality in the low technology region but makes the income distribution less equal in the high technology region.

Panel (a) of Figure 8 shows the overall effect of the different policies on income inequality in the whole economy. All policies decrease inequality 


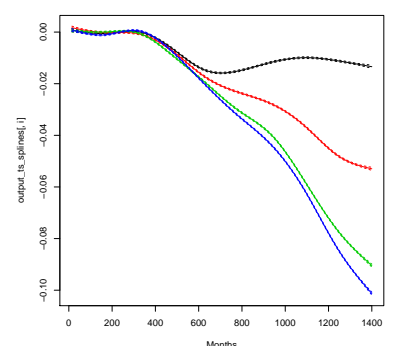

(a)

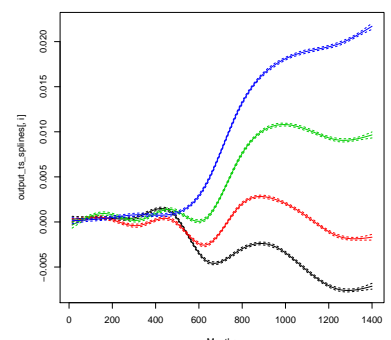

(b)

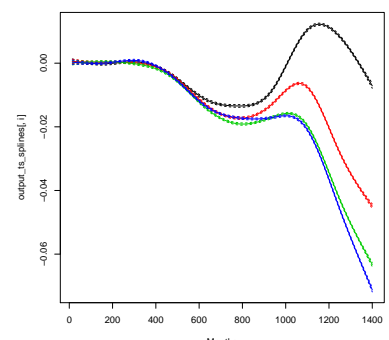

(c)

Figure 8: Effect of the different technology policies on the Gini coefficient of income in the whole economy (a), in region 1 (b) and in region 2 (c) (color code: $\alpha=0$ : black, $\alpha=0.1$ : red, $\alpha=0.2$ : green, $\alpha=0.3$ : blue).

in the default scenario. A more equal overall economy emerges with the technology policy for basically two reasons. First, the convergence process between the two regions brings the average income levels of workers in region 2 closer to the average income of workers in region 1 . Secondly, the technology policy has a within region effect on income distribution. As is shown in panels (b) and (c) of Figure 8 the effect of the policies on the inequality within a region differs qualitatively between region 1 and the target region 2 .

In region 2 the targeted policies bring more firms to the technological frontier resulting in a reduction in heterogeneity between firms and more equal wages for workers. To some extent the segregated labor market driven by the firms' productivity distribution is overcome. This can be illustrated by considering the effect of the policies on the ratio of wage offers, specific skills and output between the groups of firms with productivity above and below the median. As can be seen in Figure 9 the targeted policies reduce the ratio of the quality of physical capital between the two groups (see panel (a)), which then allows more firms in the lower productivity group to hire workers with an employment history at high-tech firms. This leads to a reduction of heterogeneity with respect to specific skills between firms (panel (b)) and reduces the strength of the phenomenon that low-tech firms have to make higher base wage offers in order to be able to hire (panel (c)). Clearly, the effects of the policies on base wage offers and specific skills increases the incentives of firms in the lower part of the productivity distribution to invest in high vintages, which reinforces the direct effect of the targeted subsidies on vintage choice. For the non-targeted policy none of these effects emerge since, as discussed above, this policy has no positive implications for technology choice, that would trigger such second order effects. 


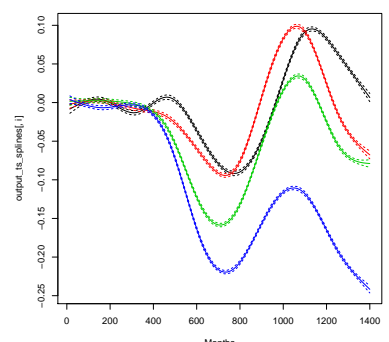

(a)

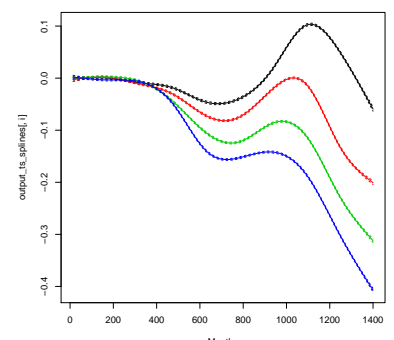

(b)

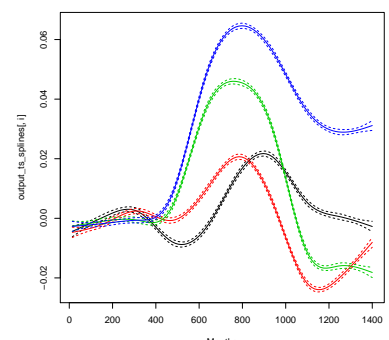

(c)

Figure 9: Effect of the different technology policies on ratios (high-tech/lowtech firms) in region 2: quality of capital stock (a), specific skills (b) and base-wage offers (c) (color code: $\alpha=0$ : black , $\alpha=0.1$ : red, $\alpha=0.2$ : green, $\alpha=0.3$ : blue).

Considering region 1 , the first observation is that all effects of policies on the inequality are much weaker than in the target region 2 (compare the panels (b) and (c) of Figure 8). For the non-targeted policy the induced change in the Gini coefficient is only about $0.5 \%$. For a weakly targeted policy the effect is similarly small, but for $\alpha=0.3$ a more pronounced effect arises. Here inequality in region 1 is increased and, as can be seen in Figure 10 the underlying mechanism is a 'mirror image' of what we observed in region 2 . The heterogeneity of firms in region 1 both with respect to the quality of physical capital and with respect to specific skills increases. Considering the dynamics of the distribution of these variables in the firm population in region 1 (not shown here) in the scenarios with and without policy it can clearly be seen that the upper part of this distribution is hardly affected by the policy, whereas the lower part becomes much more stretched out if the dynamics is subject to the targeted technology policy. Put differently, the group of firms staying very close to the frontier evolves in approximately the same way in both scenarios. However under the targeted policy the competition from firms in region 2 becomes stronger and this implies that some firms in region 1 , that initially are only slightly weaker than the technological leaders invest at such a low rate that a considerable gap between their productivity and the frontier emerges. This is a self-reinforcing process implying that the firms at the frontier produce more output than in the scenario without the technology policy, which leads to a higher labor demand and higher relative base-wage offers of the high tech firms (see panel (c) of Figure 10). Overall, this positive effect of the technology policy on firm heterogeneity in region 1 explains the induced increase in income inequality in region 1. 


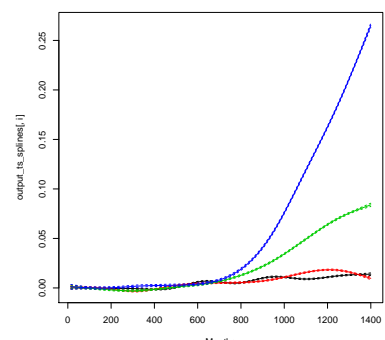

(a)

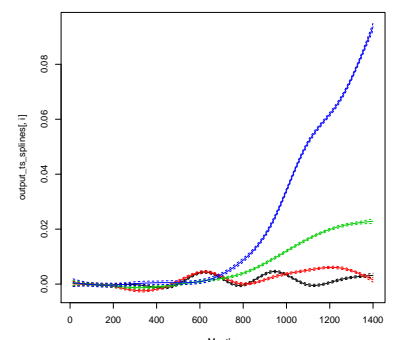

(b)

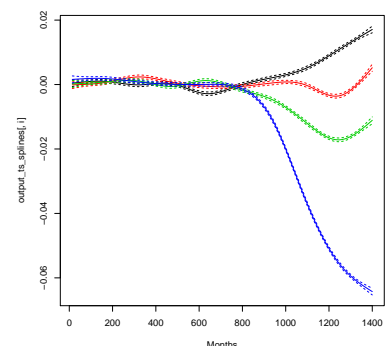

(c)

Figure 10: Effect of the different technology policies on ratios (high-tech/lowtech firms) in region 1: quality of capital stock (a), specific skills (b) and base-wage offers (c) (color code: $\alpha=0$ : black, $\alpha=0.1$ : red, $\alpha=0.2$ : green, $\alpha=0.3$ : blue).

\subsection{The Role of Flexible Labor Markets}

Our policy analysis in the previous subsection has been carried out under the assumption that the labor markets in the low-tech target region 2 has similar institutional characteristics as the labor market in the high-tech region 1 . Our results show that in such a setting the technology has to be targeted and has to be able to induce a substantial fraction of firms in the target region to invest along the technological frontier in order to foster convergence with respect to output and to reduce income inequality in the target region. As has been discussed in the Introduction many regions, at which cohesion policies of this type are targeted, are, however, characterized by relatively low wage replacement rates and strong incentives for workers to accept job-offers even if they pay less than previous employments. It is therefore an important question whether the qualitative findings of our previous discussion carry over to a setting with higher flexibility of the labor market in region 2 .

Before we study the effects of the different cohesion policies in the flexible labor market setting we should however check, in how far the dynamics in the baseline scenario without policy changes, if labor markets in region 2 are more flexible.

Figure 11 shows the dynamics of regional output and Gini coefficients in the flexible labor market scenario. Comparing this figure to Figure 2 it becomes obvious that the divergence of output between the two regions is even more pronounced if labor markets in region 2 are flexible. On the other hand, the difference in Gini coefficients is much smaller in this scenario. 


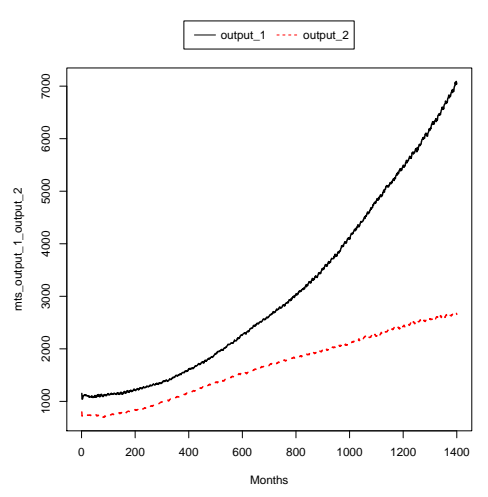

(a)

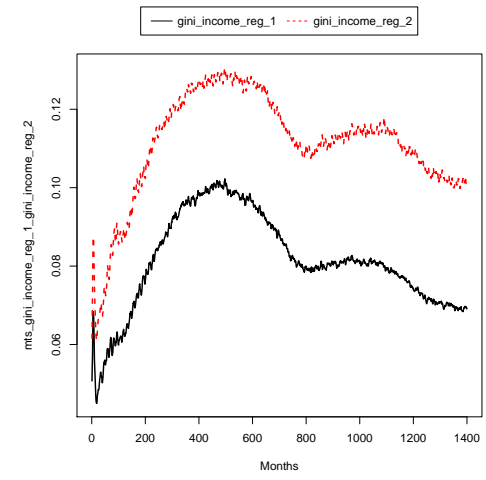

(b)

Figure 11: Dynamics of output (a) and Gini coefficient (b) in both regions

Whereas inequality in the low-tech region is still larger compared to the high tech region, the trajectories of Gini coefficients are much closer here compared to Figure 2 (b). Hence in terms of dynamics of the Gini coefficient the lowtech region with flexible labor market lies between the low-tech region with inflexible labor and the high-tech region. This observation as well as the result that in terms of per capita output the low-tech region with flexible labor market is below the low-tech region with inflexible labor market is consistent with the empirical evidence shown in Figure 2.

The reason for these changes in the dynamics is that with flexible labor markets the segregation of the workforce in region 2 into workers working only for high-tech firms and others mainly working for low tech-firms, that we observed in the baseline scenario, does not emerge. Due to the fast adjustment of reservation wages and lower replacement rates, workers who used to work for high-tech firms are willing to accept offers from low-tech firms. This implies for the low-tech firms in region 2 that they have higher chances to hire workers with high specific skills and that they are less frequently rationed on the labor market. Hence, the ratio of specific skills of workers between high- and low-tech firms is much smaller and the ratio of base wage offers between the two types of firms is much larger than in the baseline scenario (see Figure 12 (a) and (c) compared to Figure 4). As can be seen in panel (b) of this figure low-tech firms are now able to charge prices almost identical to that of high-tech firms. Therefore, high-tech firms face stronger competition both on the consumption goods and on the labor market. The wage costs of these firms are therefore higher and the investments smaller compared to the baseline scenario. The fact that a larger fraction of output in region 2 is produced by firms using capital of relatively low quality 


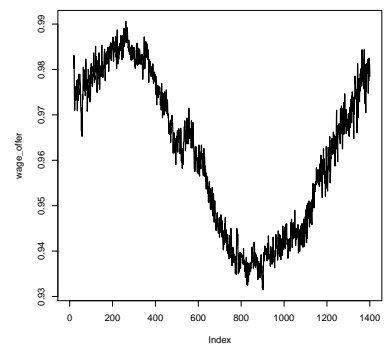

(a)

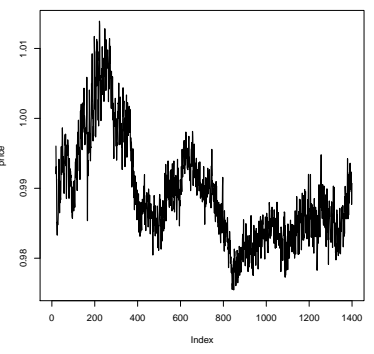

(b)

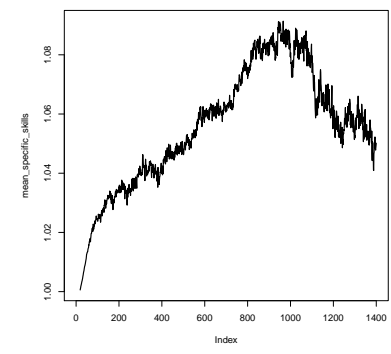

(c)

Figure 12: relative wage offers (high-tech/low-tech firms) in R2 (a), relative prices in R2 (b), relative level of specific skills in R2 (c) with a flexible labor market in $\mathrm{R} 2$.

explains why the output in region 2 is smaller with flexible labor markets compared to the baseline scenario. Furthermore these considerations imply that the heterogeneity of the firm productivity is smaller in this scenario, which explains that the trajectory of the regional Gini coefficient is below that in the scenario with inflexible labor markets.

This discussion shows that the existence of a flexible labor market in the low-tech region is not necessarily conducive for output convergence towards the high-tech region. If we, however, consider the effects of the cohesion policies, it turns out that effects are more pronounced for regions with flexible labor markets.

Result 3: The effects of the technology policies on output in region 1 is qualitatively identical under the inflexible and flexible labor market scenario. The (positive) effects on output in region 2 is substantially stronger under a flexible labor market.

Figure 13 illustrates how the effects of the policies differ between the scenarios of an inflexible and a flexible labor market in region 2. Formally, we show the penalized spline estimate of the interaction term $s_{\text {Int }}(t)$ from equation (7). Whereas, the interaction effect with respect to output in region 1 is essentially zero, for output in region 2 we obtain a significant and growing positive interaction effect for all considered policies. This means that the positive implications for the output dynamics in region 2 are much more pronounced if this region has a flexible labor market. In particular, for the non-targeted policy the positive effect on output in region 2 is almost three times stronger with flexible than with inflexible labor markets. 


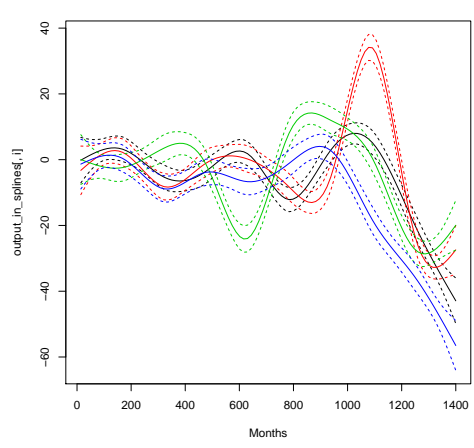

(a)

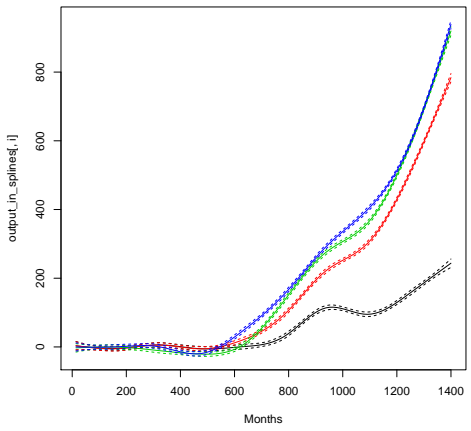

(b)

Figure 13: Difference between the two labor market scenarios of the policy effects on output in region 1 (a) and in region 2 (b)

In order to understand the stronger effects of the policies in this scenario it should be remembered that in the scenario with inflexible labor markets the main inhibitor for the policy is an upwards pressure on base-wages in region 2. This base-wage increase is to a large extend due to the frictions on the labor market in region 2 that are implied by the combination of the strong firm heterogeneity and the reluctance of workers to accepts jobs that pay substantially less than the wage in their previous employment. As discussed above, under flexible labor markets the firm heterogeneity is strongly reduced and the frictions on the labor market are much smaller. Hence, the positive effects of the technology policies on base-wage offers in region 2 are strongly reduced and the policies have a much stronger positive impact on output (and also technology) in the target region.

With respect to intra-regional income inequality we observe that the effects of the policies under flexible labor markets differ significantly from the ones observed under inflexible labor markets.

Result 4: If the labor market in the low technology region is flexible, the non-targeted policy reduces intra-regional income inequality in both regions, whereas (strongly) targeted policies increase inequality in both regions. Effects on inequality are much stronger in region 1 than in the target region 2. Overall inequality in the economy is reduced for all policies.

Result 4 is illustrated in Figure 14. In region 1 the effect on intra-regional inequality of the policies is qualitatively similar to the effects arising if the 


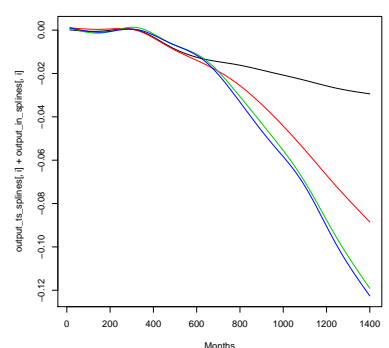

(a)

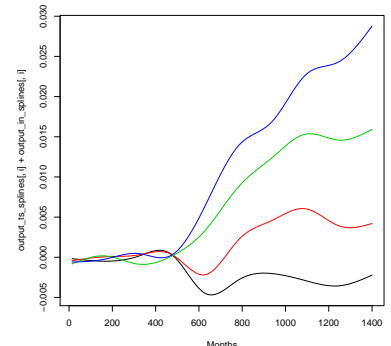

(b)

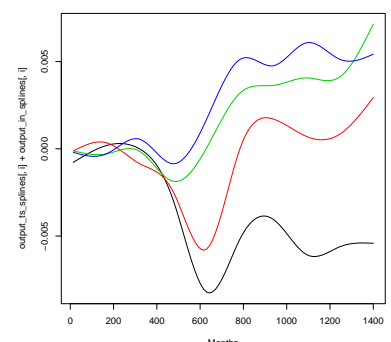

(c)

Figure 14: Effect of the different technology policies on the Gini coefficient of income in the whole economy (a), in region 1 (b) and in region 2 (c) in the flexible labor market scenario. (color code: $\alpha=0$ : black, $\alpha=0.1$ : red, $\alpha=0.2$ : green, $\alpha=0.3$ : blue).

labor market in region 2 is inflexible (compare panels (b) of Figures 14 and 8). In the target region the effects are however quite different. First it should be noted that the effects of the policies on the region 2 Gini coefficient are much smaller than in the inflexible labor market scenario. Second, in particular for the strongly targeted policies the inequality reducing effect disappears. This is mainly due to the fact that under flexible labor markets the mobility of workers between high- and low-tech firms is much stronger and therefore there is no segregation of workers in groups working for high- and low-tech firms, respectively. In such a scenario, due to the targeted policies more firms invest at the frontier implying that all workers profit in a similar way rather than that a large group of workers moves from the group of 'low-tech workers' to the group of 'high-tech workers' as it was observed in the inflexible labor market scenario. Therefore, the policy does not have a strong inequality reducing effect in region 2 under flexible labor markets. The reason for the weak positive effect on the Gini coefficient in region 2 is that the high-tech firms in region 2 profit slightly more from the expansion in demand triggered by the subsidy. This leads to a small increase in the heterogeneity of the firm population with respect to productivity, which implies an increase in the income inequality. In spite of the fact that the targeted policies increase intra-regional inequality in both regions the overall income inequality in the economy is reduced due to positive implication of the policy for convergence. The reduction of the average income difference between the regions dominates the increase of inequality in the two regions. 


\section{Conclusions}

There are persistent and considerable gaps in income per capita across European countries. Moreover, countries with lower per capita incomes are facing a more unequal distribution of incomes that has risen since the fall of the iron curtain. It is a major goal of European policymakers to foster convergence of incomes between and within regions. To this end sizable resources are spent on transfers to weakly performing regions under the umbrella of the ERDF. A prominently featuring policy is the subsidization of firms' investments.

We investigated the effectiveness of such a policy with respect to the convergence of regions and the income distribution under various scenarios which are characterizing the target regions' economic and institutional setups. The conjecture was that it is by no means clear to what extent a policy incentivizing firms to invest in better technologies can actually help achieving the policy goals when countries may be lacking the human capital to run this capital productively, do not have the public administration to survey the correct use of the transfer, and may have labor markets that function differently from those in the old member states. And indeed, our model based analysis leads to a quite distinct picture of the likely effects that we already summarized as Results in section 4.3 .

Rather than replicating these results here, we would like to emphasize the potentially insightful approach of using an agent-based macroeconomic model for the evaluation of transfer policies. We believe that our simulation based approach to evaluating (EU) policies is a complementary tool to empirical studies. A model based analysis as ours makes it possible to look into the effectiveness of policies under different time-horizons. Very often empirical studies can only take a snap shot of the effects of the policy under investigation. When it comes to policies that explicitly target long-run goals such as economic convergence evaluation tools should be able to also look into the longer run effects. A macroeconomic analysis with a sound microfoundation also let's us analyze outcome variables which are of high policy relevance for which real world data, however, very often does not exist or is of poor quality. The poor data on income distributions may serve as an example. Finally, and perhaps most importantly, this agent-based macroeconomic model allows for an investigation of the economic mechanisms underlying the policy outcomes rather than leaving the policymaker with a statement that the policy works or does not work without giving the reasons why this might be so. 


\section{References}

Aghion, P., E. Caroli, and C. Garcia-Penalosa (1999): "Inequality and economic growth: the perspective of the new growth theories," Journal of Economic Literature, 37, 1615-1660.

Aiello, F. And V. Pupo (2012): "Structural funds and the economic divide in Italy," Journal of Policy Modeling, 34, 403-418.

Allen, T. And C. Carroll (2001): "Individual learning about consumption," Macroeconomic Dynamics, 5, 255-271.

Arifovic, J., J. Bullard, And O. Kostyshyna (2012): "Social learning and monetary policy rules," The Economic Journal, DOI: 10.1111/j.14680297.2012.02525.x.

Ashraf, Q., B. Gershman, And P. Howitt (2011): "Banks, Market Organization, and Macroeconomic Performance: An Agent-Based Computational Analysis," NBER working paper 17102.

(2013): "How Inflation Affects Macroeconomic Performance: An Agent-Based Computational Investigation," Macroeconomic Dynamics, forthcoming.

Becker, S. O., P. H. EgGer, And M. von Ehrlich (2010): "Going NUTS: The effect of EU structural funds on regional performance," Journal of Public Economics, 94, 578-590.

(2013): "Absorptive capacity and the growth and investment effects of regional transfers: a regression discontinuity design with heterogeneous treatment effects," Amercian Economic Journal: Economic Policy, 5, 2977.

Beugelsdijk, M. And S. Eijffinger (2005): "The effectiveness of structural policy in the European Union: an empirical analysis for the EU-15 in 1995-2001," Journal of Common Market Studies, 43, 207-253.

Boldrin, M. And F. CAnova (2001): "Inequality and convergence in Europe's regions: reconsidering European regional policies," Economic Policy, 16, 206-245.

Burda, M. And A. Mertens (2001): "Estimating Wage Losses of Displaced Workers in Germany," Labour Economics, 8, 15-42. 
Burnside, C. And D. Dollar (2000): "Aid, policies, and growth," American Economic Review, 90, 847-868.

Campano, F. and D. Salvatore (2006): Income Distribution, Oxford: Oxford University Press.

Cappelen, A., F. Castellaci, J. Fagerberg, and B. Verspagen (2003): "The impact of regional support on growth and convergence in the European Union," Journal of Common Market Studies, 41, 621-644.

Carroll, C. (1997): "Buffer-stock saving and the life cycle/permanent income hypothesis," The Quarterly Journal of Economics, 112, 1-55.

Dawid, H., S. Gemkow, P. Harting, And M. Neugart (2012a): "Labor market integration policies and the convergence of regions: the role of skills and technology diffusion," Journal of Evolutionary Economics, 22, 543-562.

Dawid, H., S. Gemkow, P. Harting, S. van der Hoog, and M. NeuGART (2012b): "The Eurace@Unibi Model: An Agent-Based Macroeconomic Model for Economic Policy Design," Report, Bielefeld University: http://www.wiwi.uni-bielefeld.de/fileadmin/vpl1/Publications/Agentbased_Modelling/eurace_unibi_descr_2012.pdf.

Dawid, H. And P. Harting (2012): "Capturing Firm Behavior in AgentBased Models of Industry Evolution and Macroeconomic Dynamics," in Applied Evolutionary Economics, Behavior and Organizations, ed. by G. Bünsdorf, Edward-Elgar, 103-130.

Dawid, H., P. Harting, And M. Neugart (2014): "Economic Convergence: Policy Implications from a Heterogeneous Agent Model," forthcoming in the Journal of Economic Dynamics and Control.

De Dominicis, L., R. J. G. M. Florax, And H. L. F. De Groot (2008): "A meta-analysis on the relationship between income inequality and economic growth," Scottish Journal of Political Economy, 55, 654-682.

Delli Gatti, D., M. Gallegati, B. Greenwald, A. Russo, And J. Stiglitz (2010): "The financial accelerator in an evolving credit network," Journal of Economic Dynamics and Control, 34, 1627-1650.

Dosi, G., G. Fagiolo, And A. Roventini (2010): "Schumpeter meeting Keynes: a policy-friendly model of endogenous growth and business cycles," Journal of Economic Dynamics and Control, 34, 1748-1767. 
Dosi, G., F. Malerba, O. Marsili, and L. Orsenigo (1997): "Industrial structures and dynamics: evidence, interpretations and puzzles," Industrial and Corporate Change, 6, 3-24.

Ederveen, S., L. F. H. De Groot, And R. Nahuis (2006): "Fertile soil for structural funds? A panel data analysis of the conditional effectiveness of European cohesion policy," Kyklos, 59, 17-42.

European Commission (2011): "Employment and Social Development in Europe 2011," Report from the Commission.

Fabiani, S., M. Druant, I. Hernando, C. Kwapil, B. Landau, C. Loupias, F. Martins, T. Matha, R. Sabbatini, H. Stahl, and A. Stokman (2006): "What firm surveys tell us about price-setting behavior in the euro area," International Journal of Central Banking, 2, 3-47.

FagGio, G., K. Salvanes, And J. van Reenen (2010): "The Evolution of Inequality in Productivity and Wages: Panel Data Evidence," Industrial and Corporate Change, 19, 1919-1951.

Gintis, H. (2007): "The dynamics of general equilibrium," Economic Journal, 117, 1280-1309.

Kauermann, G., G. Claeskens, and J. D. Opsomer (2009): "Bootstrapping for penalized spline regression," Journal of Computational and Graphical Statistics, 18, 126-146.

Krivobokova, T. and G. Kauermann (2007): "A note on penalized spline smoothing with correlated errors," Journal of the American Statistical Association, 102, 1328-1337.

Kuznets, S. (1955): "Economic growth and income inequality," American Economic Review, 45, 1-28.

Malhotra, N. (1984): "The Use of Linear Logit Models in Marketing Research," Journal of Marketing research, 11, 20-31.

Nagle, T. And J. Hogan (2006): The Strategy and Tactics of Pricing: A Guide to Growing More Profitably, New Jersey: Pearson Prentice Hall.

OECD (2007): "Employment outlook," OECD Publishing, Paris.

Raberto, M., A. Telgio, And S. Cincotti (2012): "Debt, deleveraging and business cycles: an agent-based perspective," Economics, The OpenAccess, Open-Assessment E-Journal, 6. 
Ramajo, J., M. A. Marquez, G. J. D. Hewings, and M. M. Salinas (2008): "Spatial heterogeneity and interregional spillovers in the European Union: do cohesion policies encourage convergence across regions?" European Economic Review, 52, 551-567.

Silver, E., D. Pyke, And R. Peterson (1998): Inventory Management and Production Planing and Scheduling, John Wiley \& Sons.

Stock, J. And M. WATson (1999): "Business cycle fluctuations and U.S. macroeconomic time series," in Handbook of Macroeconomics, Vol. 1, ed. by J. Taylor and M. Woodford, Amsterdam: Elsevier, 3-64.

van Vliet, O. And K. Caminada (2012): "Unemployment replacement rates dataset among 34 welfare states, 1971-2009: an update, extension and modification of the Scruggs' welfare state entitlements data set," NEUJOBS Special Report no. 2, January 2012.

Wolf, S., S. Fuerst, A. Mandel, W. Lass, D. Lincke, F. PabloMARTI, AND C. JAEGER (2012): "Lagom regiO - a multi-agent model of several economic regions," to appear in: Proceedings of the 100th Dahlem Conference, New Approaches in Economics after the Financial Crisis.

Wood, S. (2011): "Fast stable restricted maximum likelihood and marginal likelihood estimation of semiparametric generalized linear models," Journal of the Royal Statistical Society, 73, 3-36. 


\section{Previously published SFB 882 Working Papers:}

Diewald, Martin / Faist, Thomas (2011): From Heterogeneities to Inequalities: Looking at Social Mechanisms as an Explanatory Approach to the Generation of Social Inequalities, SFB 882 Working Paper Series No. 1, DFG Research Center (SFB) 882 From Heterogeneities to Inequalities, Bielefeld.

Busch, Anne (2011): Determinants of Occupational Gender Segregation: Work Values and Gender (A)Typical Occupational Preferences of Adolescents, SFB 882 Working Paper Series No. 2, DFG Research Center (SFB) 882 From Heterogeneities to Inequalities, Research Project A3, Bielefeld.

Faist, Thomas (2011): Multiculturalism: From Heterogeneities to Social (In)Equalities, SFB 882 Working Paper Series No. 3, DFG Research Center (SFB) 882 From Heterogeneities to Inequalities, Research Project C3, Bielefeld.

Amelina, Anna (2012): Jenseits des Homogenitätsmodells der Kultur: Zur Analyse von Transnationalität und kulturellen Interferenzen auf der Grundlage der hermeneutischen Wissenssoziologie, SFB 882 Working Paper Series No. 4, DFG Research Center (SFB) 882 From Heterogeneities to Inequalities, Research Project C3, Bielefeld.

Osmanowski, Magdalena / Cardona, Andrés (2012): Resource Dilution or Resource Augmentation? Number of Siblings, Birth Order, Sex of the Child and Frequency of Mother's Activities with Preschool Children, SFB 882 Working Paper Series No. 5, DFG Research Center (SFB) 882 From Heterogeneities to Inequalities, Research Project A1, Bielefeld.

Amelina, Anna / Bilecen, Başak / Barglowski, Karolina / Faist, Thomas (2012): Ties That Protect? The Significance of Transnationality for the Distribution of Informal Social Protection in Migrant Networks, SFB 882 Working Paper Series No. 6, DFG Research Center (SFB) 882 From Heterogeneities to Inequalities, Research Project C3, Bielefeld.

Alemann, Annette von / Beaufaÿs, Sandra / Reimer, Thordis (2012): Gaining Access to the Field of Work Organizations with the Issue of "Work-Family-Life Balance" for Fathers, SFB 882 Working Paper Series No. 7, DFG Research Center (SFB) 882 From Heterogeneities to Inequalities, Research Project B5, Bielefeld.

Kaiser, Till (2012): Haben gebildetere Mütter gewissenhaftere Kinder? Soziale Herkunft und Persönlichkeitsentwicklung im frühkindlichen Alter, SFB 882 Working Paper Series No. 8, DFG Research Center (SFB) 882 From Heterogeneities to Inequalities, Research Project A1, Bielefeld.

Gusy, Christoph / Müller, Sebastian (2012): Social Construction of Heterogeneity Indicators and their Relationship to Law. The Example of Guiding Principles in Immigration Law, 
SFB 882 Working Paper Series No. 9, DFG Research Center (SFB) 882 From Heterogeneities to Inequalities, Research Project C4, Bielefeld.

Liebig, Stefan / May, Meike / Sauer, Carsten / Schneider, Simone / Valet, Peter (2012): Inequality Preferences in Interviewer- and Self-Administered Interviews, SFB 882 Working Paper Series No. 10, DFG Research Center (SFB) 882 From Heterogeneities to Inequalities, Research Project A6, Bielefeld.

Fauser, Margit / Voigtländer, Sven / Tuncer, Hidayet / Liebau, Elisabeth / Faist, Thomas / Razum, Oliver (2012): Transnationality and Social Inequalities of Migrants in Germany, SFB 882 Working Paper Series No. 11, DFG Research Center (SFB) 882 From Heterogeneities to Inequalities, Research Project C1, Bielefeld.

Freistein, Katja / Koch, Martin (2012): Global Inequality and Development. Textual Representations of the World Bank and UNDP, SFB 882 Working Paper Series No. 12, DFG Research Center (SFB) 882 From Heterogeneities to Inequalities, Research Project C5, Bielefeld.

Golsch, Katrin (2013): Shall I Help You My Dear? Examining Variations in Social Support for Career Advancement within Partnerships, SFB 882 Working Paper Series No. 13, DFG Research Center (SFB) 882 From Heterogeneities to Inequalities, Research Project A3, Bielefeld.

Bröckel, Miriam / Busch, Anne / Golsch, Katrin (2013): Headwind or Tailwind - Do Partner's Resources Support or Restrict a Promotion to a Leadership Position in Germany?, SFB 882 Working Paper Series No. 14, DFG Research Center (SFB) 882 From Heterogeneities to Inequalities, Research Project A3, Bielefeld.

Cardona, Andrés (2013): Closing the Group or the Market? The Two Sides of Weber's Concept of Closure and Their Relevance for the Study of Intergroup Inequality, SFB 882 Working Paper Series No. 15, DFG Research Center (SFB) 882 From Heterogeneities to Inequalities, Research Project A1, Bielefeld.

Friedhoff, Stefan / Meier zu Verl, Christian / Pietsch, Christian / Meyer, Christian / Vompras, Johanna / Liebig, Stefan (2013): Social Research Data. Documentation, Management, and Technical Implementation at SFB 882, SFB 882 Working Paper Series, No. 16, DFG Research Center (SFB) 882 From Heterogeneities to Inequalities, Project "Information and Data Infrastructure" (INF), Bielefeld.

Reinecke, Jost / Stemmler, Mark / Sünkel, Zara / Schepers, Deborah / Weiss, Maren / Arnis, Maria / Meinert, Julia / Kucur-Uysal, Burcu / Pöge, Andreas / Wallner, Susanne / Wittenberg, Jochen (2013): The Development of Deviant and Delinquent Behavior over the Life Course in the Context of Processes of Social Inequalities, SFB 882 Working Paper Series No. 17, DFG Research Center (SFB) 882 From Heterogeneities to Inequalities, Research Project A2, Bielefeld.

Hense, Andrea / Edler, Susanne / Liebig, Stefan (2013): Individual Determinants of Recalls, SFB 882 Working Paper Series No. 18, DFG Research Center (SFB) 882 From Heterogeneities to Inequalities, Research Project B4, Bielefeld. 
Bilecen, Başak (2013): Analyzing Informal Social Protection Across Borders: Synthesizing Social Network Analysis with Qualitative Interviews, SFB 882 Working Paper Series No. 19, DFG Research Center (SFB) 882 From Heterogeneities to Inequalities, Research Project C3, Bielefeld.

Schunck, Reinhard / Abendroth, Anja-Kristin / Diewald, Martin / Melzer, Silvia Maja / Pausch, Stephanie (2013): What do Women and Men Want? Investigating and Measuring Preference Heterogeneity for Life Outcomes using a Factorial Survey, SFB 882 Working Paper Series No. 20, DFG Research Center (SFB) 882 From Heterogeneities to Inequalities, Research Project B3, Bielefeld.

Sauer, Carsten / Valet, Peter / Liebig, Stefan (2013): The Impact of Within and Between Occupational Inequalities on People's Justice Perceptions Towards their Own Earnings, SFB 882 Working Paper Series No. 21, DFG Research Center (SFB) 882 From Heterogeneities to Inequalities, Research Project A6, Bielefeld.

Schneider, Simone / Valet, Peter (2013): Social Comparison Orientations and their Consequences for Justice Perceptions of Earnings, SFB 882 Working Paper Series No. 22, DFG Research Center (SFB) 882 From Heterogeneities to Inequalities, Research Project A6, Bielefeld.

Cardona, Andrés (2013): The Programmatic Bias in the Discussion on Social Mechanisms in Sociology, SFB 882 Working Paper Series No. 23, DFG Research Center (SFB) 882 From Heterogeneities to Inequalities, Research Project A1, Bielefeld.

Hille, Adrian / Schupp, Jürgen (2013): How Learning a Musical Instrument Affects the Development of Skills, SFB 882 Working Paper Series No. 24, DFG Research Center (SFB) 882 From Heterogeneities to Inequalities, Research Project A1, Bielefeld.

Faist, Thomas (2014): "We are all Transnationals now": The Relevance of Transnationality for Understanding Social Inequalities, SFB 882 Working Paper Series No. 25, DFG Research Center (SFB) 882 From Heterogeneities to Inequalities, Research Project C1, Bielefeld.

Lohmann, Henning / Ferger, Florian (2014): Educational Poverty in a Comparative Perspective: Theoretical and Empirical Implications, SFB 882 Working Paper Series No. 26, DFG Research Center (SFB) 882 From Heterogeneities to Inequalities, Research Project A5, Bielefeld.

Freistein, Katja / Koch, Martin (2014): The Effects of Measuring Poverty - Indicators of the World Bank, SFB 882 Working Paper Series No. 27, DFG Research Center (SFB) 882 From Heterogeneities to Inequalities, Research Project C5, Bielefeld.

Andernach, Björn / Schunck, Reinhard (2014): Investigating the Feasibility of a Factorial Survey in a CATI, SFB 882 Working Paper Series No. 28, DFG Research Center (SFB) 882 From Heterogeneities to Inequalities, Research Project B3, Bielefeld.

Sauer, Carsten (2014): A Just Gender Pay Gap? Three Factorial Survey Studies on Justice Evaluations of Earnings for Male and Female Employees, SFB 882 Working Paper Series No. 29, DFG Research Center (SFB) 882 From Heterogeneities to Inequalities, Research Project A6, Bielefeld. 
Berger, Johannes (2014): Dringend erforderlich: eine stärker vereinheitlichte soziologische Ungleichheitsforschung, SFB 882 Working Paper Series No. 30, DFG Research Center (SFB) 882 From Heterogeneities to Inequalities, Research Project Z, Bielefeld.

Karsch, Anna (2014): Geschlechtstypische Unterschiede in den Berufspräferenzen deutscher Jugendlicher, SFB 882 Working Paper Series No. 31, DFG Research Center (SFB) 882 From Heterogeneities to Inequalities, Research Project A3, Bielefeld.

Barglowski, Karolina (2014): Social Classifications and Inequalities: Ideologies of Mobility, Care and Work in Transnational Families, SFB 882 Working Paper Series No. 32, DFG Research Center (SFB) 882 From Heterogeneities to Inequalities, Research Project C3, Bielefeld.

Sauer, Carsten / Valet, Peter / Liebig, Stefan (2014): Ungleichheiten am Arbeitsmarkt und die Gerechtigkeitswahrnehmung von Erwerbseinkommen, SFB 882 Working Paper Series No. 33, DFG Research Center (SFB) 882 From Heterogeneities to Inequalities, Research Project A6, Bielefeld. 